\title{
TOPONIMIA DE PONTECESO Y DE SU MUNICIPIO
}

\author{
por \\ ISIDORO MILLÁN GONZÁLEZ-PARDO
}

\begin{abstract}
O orixinal do texto que sai hoxe á luz pública, enviouse no seu día, en 1979, ó Presidente da corporación solicitante, o Alcalde de Ponteceso, pra que surtise os efeitos de emenda ou restitución toponímica que o Concello pretendía. Apenas si acadou outra difusión, como era previsto, cá propia e limitada de tal destino. Pois que me decato hoxe de que as máis das súas novidades e conclusións toponímicoetimolóxicas conservan aínda vixencia e xeral interese, saco agora este escrito da súa condición de inédito, e fágoo nas páxinas de CEG, órgano do Instituto de Estudios Galegos P. Sarmiento, ó que se endereitara naquel tempo a demanda de dictame. encomendándoo nominalmente á persoa que logo o formulou.

Reteño o teor do texto cáseque na súa íntegra literalidade. Procedo somente a lixeiros retoques ou algunhas mudanzas na expresión. Intercalo, emporiso, na ringuileira das notas, algunha que outra que compoño agora, distinguindoas das anteriores pola posposición dun a ou $\mathrm{b}$ a idéntico guarismo do da nota que precede a cada unha das engadidas.

Non mudo en nada, como axeitadas que estaban á liña de prudencia requerida na primeira fase da nosa recuperación toponímica, as normas e cautelas que recomendei daquela. Deixo tamén o texto do informe na lingua castelá na que entón o formulei.

Cáseque, pois, ó pe da letra, dicía así o meu dictame:
\end{abstract}

\section{"SR. ALCALDE E ILUSTRÍSIMO AYUNTAMIENTO DE PONTE-CESO.}

A últimos de Junio se recibió en el Instituto P. Sarmiento de Estudios Gallegos atento oficio de V.S. en que solicitaba informe técnico "con el fin de restaurar todos los topónimos de este municipio y de recuperar sus nombres originales gallegos más importantes".

"CUADERNOS DE ESTUDIOS GALLEGOS", Tomo XLI, Fascículo 106, Santiago 1993-94. 
Quien suscribe este informe era el destinatario nominal de la solicitud, pero no pudo atenderla enseguida a causa de sus ocupaciones profesionales en aquellas fechas y de la participación en un Congreso, que me hacían imposible el desplazamiento a Ponte-Ceso para las inexcusables comprobaciones lingüísticas "in situ". El estudio de una serie de topónimos de determinada zona, con el fin de establecer su actual norma gráfica, no se puede realizar con garantía de pleno acierto si se carece de contacto suficiente con aquella.

Los días 29 de Julio y 5 de Agosto hice cortas paradas en Ponte-Ceso y el día 5 del mes en que escribo emplée media jornada en recorrer parte de su término. En estos desplazamientos conseguí visión personal de bastantes sitios y realicé indagaciones orales para la mejor solución de algunos problemas que no tenía aún aclarados.

Fundado en el conjunto de dátos allegados emito el presente dictamen, que constará de los siguientes apartados:

I) PRINCIPIOS Y CRITERIOS GENERALES.

II) LISTA DE TOPÓNIMOS PROPUESTA Y LISTA DE SOLUCIONES RECOMENDADAS.

III) COMENTARIO PARTICULARIZADO DE ALGUNOS DE ESTOS TOPÓNIMOS.

\section{I PRINCIPIOS Y CRITERIOS GENERALES}

$\left.1^{\circ}\right)$ El motivo impulsor de la decisión del Ayuntamiento de Ponte-Ceso, que es el de restaurar o defender la toponimia tradicional y legítima del Municipio, es, o debería ser, superfluo proclamar que responde a la única actitud patriótica y culta en esta materia.

Puesto que España es variedad, históricamente integrada, de pueblos y lenguas, con sus específicos legados, el ignorar, despreciar o mermar, a sabiendas, los elementos distintos que los constituyen - lingüísticos, artísticos o etnográficos- atenta no sólo contra el bien particular, sino contra el común patrimonio hispano.

$\left.2^{a}\right)$ Los topónimos tradicionales son porción esencial del acervo lingüístico, pero, por su índole característica, condensan un contenido múltiple -léxico, geográfico, arqueológico, institucional, etc.- que las cien- 
cias histórico-culturales valoran, y procuran tutelar hoy, extraordinariamente.

Esta enseñanza interna, permanente, de los nombres de lugar, sólo la transmiten en forma asequible cuando, mediante la armonización normada de pronunciación y grafía, se los conserva con mayor pureza. Es ello lo que permite rastrear mejor, o determinar con éxito, su época de imposición y su étimo.

$\left.3^{\circ}\right)$ Dos son, en síntesis, las posturas adoptables en el revestimiento gráfico de los topónimos gallegos:

a) perseverar, si bien descartando burdos errores, en la escritura usual, muchas veces antigua y legítima, de cada uno de ellos, aunque esto pueda incitar a su interpretación y pronunciación castellanizante por propios y extraños;

b) ajustar también el caudal léxico de la toponimia a la escritura oficialmente recomendada de la lengua a que pertenece, sacrificando a esto, en algún caso, las grafías más etimológicas o históricas que le correspondían.

Una y otra postura, que tienen defensores entre filólogos y toponimistas gallegos de hoy, son reflejo de una más amplia y gravemente crítica vacilación normativa en torno a la lengua: o la de optar por la grafía antigua o más tradicional, con mayor o menor grado de acercamiento a las soluciones y grafemas lusitanos, o la de preferir la ortografía gallega innovada, con mayor o menor grado de aproximación a las soluciones del habla popular o al remedo de las rurales.

El retraso en que prospere, entre estas posturas y sus variantes, una orientación unívoca, o matizadamente conciliadora, se debe en su mayor parte a la incompetencia y anulación de autoridad de la institución que, por título y lema, debería dictar normas válidas y, conectándose con esto en círculo vicioso, a la indigencia y desbarajuste, previsiblemente cada vez mayor, de la alfabetización y docencia del gallego.

Esta situación obliga a un lingüista, responsable de un informe técnico sobre gallego, a justificar su opción normativa. Es, en mi caso, la opción b), puesto que la defensa, "hic et nunc", del habla gallega real —que es la materia prima lingüística con que los gallegos contamos y susceptible de norma- en su colisión íntima y cotidiana con el castellano escrito y hablado, precisa de "corazas" gráfico-fonéticas diferenciantes, que la opción b) de ningún modo hoy le proporcionaría, y que no podría ser compensada por la visión, aún futurista en este momento, de una convergencia 
—posible y deseable en algunos aspectos, pero siempre parcial— con el portugués.

$4^{\circ}$ ) Adviértase que, por lo general, no existen en Galicia otras denominaciones lingüísticamente legítimas de sus antiguos lugares que las tradicionales gallegas, puesto que los nombres "castellanos" de los mismos, o son deformaciones plenas o parciales de los genuinos gallegos - verbigracia, Allones o Niñones - , o versiones idiomáticas foráneas, completas o a medio camino - verbigracia, Puente-Ceso, Puente-Areas - pero que no han llegado a calar, por lo más común, en los estratos populares - que son los auténticamente autorizados- de la población gallego-parlante, o bien son formas que adolecen de otras bastardías análogas.

Este hecho, y las consecuencias que de él se desprenden, refuerzan la justificación del intento purificador emprendido por el Concejo de PonteCeso.

$5^{\circ}$ ) Caso distinto y respetable es el de algunas imposiciones primarias de nombres geográficos que puedan haberse hecho en castellano, en la época de coexistencia bilíngüe que, más retartada o somera en zonas rurales, fue cundiendo a partir del siglo XVI en forma muy desigual y paulatina.

Estos nombres, por lo común, han recibido entre los hablantes nativos una galleguización parcial - verbigracia, Os Anxeles - que, si es popular y no abiertamente inculta, deberá por el momento ser respaldada oficialmente. Se les aplica la condición de los préstamos, incompletamente asimilados en la lengua de entrada.

Si es una forma plenamente castellana — lo que es más inusitado— la única sentida y divulgada por los hablantes, bien en virtud de una imposición primaria bien por la sustitución total y consolidada de otra gallega que le antecedía, un criterio de respeto a las realidades "in possessione" y de prudencia operativa, aconsejará mantenerla, de momento al menos, en el Nomenclator oficial. Pero estos casos son muchos menos de lo que se piensa.

Es claro que sólo el conocimiento a fondo de la zona toponímica y lingüística estudiada permitirá aplicar, en cada uno de estos supuestos, la solución más justa y aceptable para los hablantes nativos.

$\left.6^{\circ}\right)$ Las directrices y criterios que quedan expuestos basarán diversos consejos o recomendaciones de este informe, y me remitiré, en su caso, a

"CUADERNOS DE ESTUDIOS GALLEGOS", Tomo XLI, Fascículo 106, Santiago 1993-94. 
los apartados en que se explican.

Aunque la lista sometida a mi dictamen del repertorio municipal de PonteCeso no precisa de muchas ni graves reformas, era conveniente sentar a propósito de ella principios de carácter general, que reproducen o se agregan a los que propugné en informes toponímicos anteriores ${ }^{1 / 1 a}$.

El apartado III) COMENTARIO PARTICULARIZADO, en que se glosan muchos de estos topónimos va, por lo general, mucho más allá del fin de justificar las enmiendas que afectan a algunos. Pretende, por una parte, hacer palpar tangiblemente la riqueza de información variadísima que nos transmite la toponimia y que, según se dijo, se nos asegura con una transcripción fiel; y, en segundo lugar, sientan bases, en más de un caso, para interpretar debidamente formas símiles o comparables de la toponimia general gallega. Obedece, por tanto, en definitiva, al deseo de aumentar el conocimiento y el respeto de este precioso legado de nuestra tradición histórica.

${ }^{1}$ Informe sobre 216 topónimos del término municipal de Santiago de Compostela. Fue solicitado por el Ayuntamiento de esta ciudad a la Academia Gallega y se emitió por el autor del presente, en 16-V-1976. Quedó, a lo que me conste, inaplicado. Inédito.

Sobre el nombre de Pontedeume y otros topónimos de su término municipal. Solicitado por el Ayuntamiento también a la Academia Gallega y redactado por el autor de este, a 1-VIII-1976. Se aplicó en cuanto al objeto de la consulta y se publicó después como artículo bajo el título: Los nombres de Pontedeume y su río, el castro de Ombre y la batalla de Pontumio, en VERBA, vol. 5 (1978), pp. 25-46.

${ }^{\text {la }} \mathrm{El}$ informe citado en segundo lugar en la nota que precede cuajó luego, por instancias de publicación que se me hicieron, en el estudio mucho más amplio, Toponimia del Concejo de Pontedeume y Cartas Reales de su Puebla y Alfoz, Diputación Provincial de Coruña, 1987.

"CUADERNOS DE ESTUDIOS GALLEGOS", Tomo XLI, Fascículo 106, Santiago 1993-94. 
II

\section{LISTA PROPUESTA Y LISTA RECOMENDADA²}

\begin{tabular}{|c|c|c|}
\hline & Dice & Debe decir \\
\hline 000 & PUENTE-CESO & PONTE-CESO \\
\hline 100 & ALLONES & ANLLÓNS \\
\hline 101 & ALLONES DE ARRIBA & ANLLÓNS DE ARRIBA \\
\hline 102 & ALLONES GRANDE & ANLLÓNS GRANDE \\
\hline 103 & GARGA & GARGA (A) \\
\hline 104 & SAIMIA & SAÍMIA (A) \\
\hline 200 & BRANTUAS & BRANTUAS \\
\hline 201 & ANGELES & ÁNXELES (OS) \\
\hline 202 & BRANTUAS DE ABAJO & BRANTUAS DE ABAIXO \\
\hline 203 & BRANTUAS DE ARRIBA & BRANTUAS DE ARRIBA \\
\hline 300 & CORES & CORES \\
\hline 301 & BARDAYO & BARDAYO \\
\hline 302 & BARREIROS & BARREIROS (OS) \\
\hline 303 & CAMPARA & CAMPARA (A) \\
\hline 304 & CASTRO & CASTRO (O) \\
\hline 305 & CORES & CORES \\
\hline 306 & FIGUEIROA & FIGUEIROA \\
\hline 307 & LAMELA & LAMELA \\
\hline 308 & LIMIÑOA & LIMIÑOA (A) \\
\hline 309 & MIRAFLORES & MIRAFLORES \\
\hline 310 & ORADA & OURADA (A) \\
\hline 311 & RIOTORTO & RIO-TORTO \\
\hline 312 & SANTA CRUZ & SANTA CRUZ \\
\hline 313 & VILASUSO & VILADESUSO \\
\hline 400 & CORME-ALDEA & CORME-ALDEA \\
\hline 401 & ALDEA & ALDEA \\
\hline 402 & COSTA & $\operatorname{cosTA}(\mathrm{A})$ \\
\hline 403 & ESCOBIA & ESCOBIA \\
\hline 404 & FROJÁN & FROXÁN \\
\hline
\end{tabular}

\footnotetext{
${ }^{2}$ La lista remitida por el Ayuntamiento de Ponte-Ceso sigue, en general, la relación del Nomenclator, en su última edición. Hago, pues, preceder a cada topónimo los guarismos que significan la cifra que se les antepone en este catálogo. Pero, bajo el encabezamiento CORME, intercala la lista del Ayuntamiento designaciones de sitios urbanos o de lugares de esta villa, que yo serio en mi informe con letras del alfabeto, desde $a$ a $s$, inclusive.
}

"CUADERNOS DE ESTUDIOS GALLEGOS", Tomo XLI, Fascículo 106, Santiago 1993-94. 


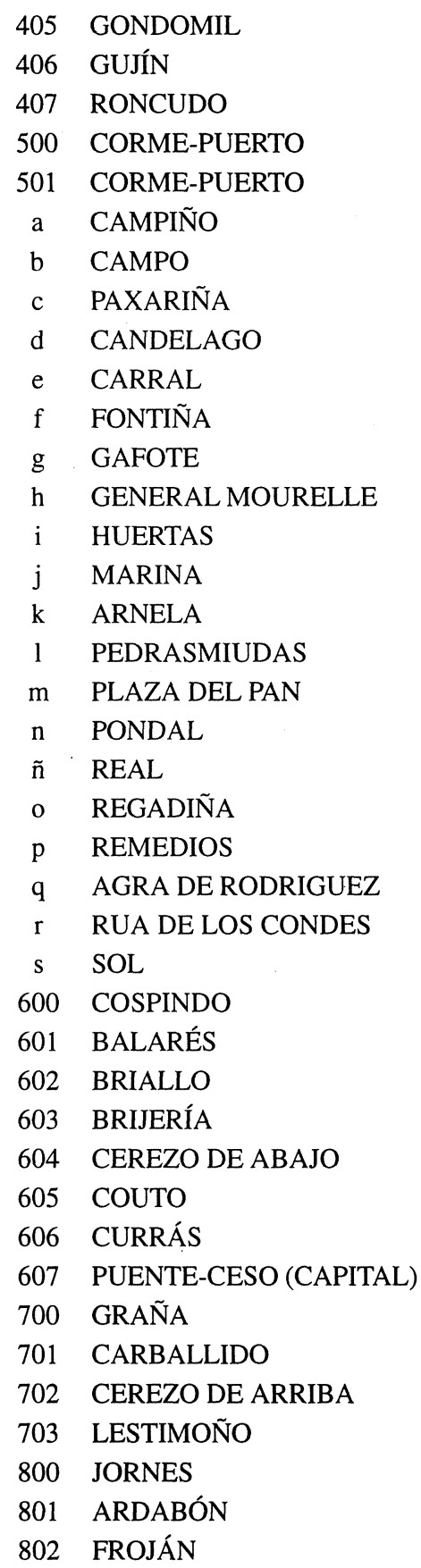

"CUADERNOS DE ESTUDIOS GALLEGOS", Tomo XLI, Fascículo 106, Santiago 1993-94. 


\begin{tabular}{|c|c|c|}
\hline 803 & JORNES & XORNES \\
\hline 804 & PONTEDONA & PONTE-DONA \\
\hline 805 & SAN ANTONIO & SAN ANTONIO \\
\hline 806 & SERGUDE & SERGUDE \\
\hline 900 & LANGUEIRÓN & LANGUEIRÓN \\
\hline 901 & CARRASQUEIRA & CARRASQUEIRA \\
\hline 902 & LANGUEIRÓN & LANGUEIRÓN \\
\hline 903 & MELCOS & MELCOS \\
\hline 904 & VITUREIRA & VITUREIRA (A) \\
\hline 1000 & NEMEÑO & NEMEÑO \\
\hline 1001 & CAMPARA & CAMPARA \\
\hline 1002 & NEMEÑO & NEMEÑO \\
\hline 1003 & PORTO DO SOUTO & PORTO DO SOUTO \\
\hline 1004 & RUEIRO & RUEIRO \\
\hline 1100 & NIÑONES & NIÑÓNS \\
\hline 1101 & NIÑONES & NIÑÓNS \\
\hline 1200 & PAZOS & PAZOS \\
\hline 1201 & AMEIJENDA & AMEIXENDA \\
\hline 1202 & PAZOS DE ABAJO & PAZOS DE ABAIXO \\
\hline 1203 & PAZOS DE ARRIBA & PAZOS DE ARRIBA \\
\hline 1204 & REBORDÁNS & REBORDÁNS \\
\hline 1205 & SALGUEIRAS & SALGUEIRAS \\
\hline 1300 & TALLO & TALLO \\
\hline 1301 & BUGALLEIRA & BUGALLEIRA \\
\hline 1302 & CASAS-NOVAS & CASAS-NOVAS \\
\hline 1303 & PARDIÑAS & PARDIÑAS \\
\hline 1304 & RIEIRO & RIEIRO (O) \\
\hline 1305 & TALLO & TALLO \\
\hline 1306 & VILASUSO & VILASUSO \\
\hline 1400 & TELLA & TELLA \\
\hline 1401 & CALLE & CALLE (A) \\
\hline 1402 & CUÑARROS & CUÑARROS \\
\hline 1403 & FONTÁN & FONTÁN \\
\hline 1404 & GÁNDARA & GÁNDARA \\
\hline 1405 & PETÓN & PETÓN (O) \\
\hline 1406 & RUEIRO & RUEIRO \\
\hline 1407 & SEIXOS & SEIXOS (OS) \\
\hline 1408 & TRABE & TRABE (A) \\
\hline 1409 & VEREDA & VEREDA \\
\hline
\end{tabular}

"CUADERNOS DE ESTUDIOS GALLEGOS", Tomo XLI, Fascículo 106, Santiago 1993-94. 


\section{III \\ COMENTARIO PARTICULARIZADO}

\section{Puente-Ceso / Ponte-Ceso}

Se impone restituir oficialmente, como nombre de todo el municipio y del lugar de la fel. de San TIRSO DE COSPINDO (=607) en que se asentó su capital, la forma legítima, PONTE-CESO, que jamás ha dejado de gozar del favor de los hablantes nativos. A la otra banda del río Anllóns, en el municipio de CABANA, fel. de SAN ESTEBO DE CESULLAS, existe el lugar homónimo de PONTE-CESO.

Son prueba los dos PONTE-CESO, a una y otra ribera del Anllóns, de la existencia sobre el río que los separa de un puente antiguo que precedió al que hoy vemos y del que ambos tomarían nombre. El que salva ahora en este punto el curso del río Anllóns frisará, a juzgar por su fábrica, en unos cien años. La inspección ocular no me permitió descubrir vestigios de estructura más primitiva, a no ser que hubiesen pertenecido a ella los restos de un viejo malecón, visibles aún a la margen izquierda del río, aguas abajo.

Que existió aquí tal puente lo corrobora la Carta Geométrica de Galicia, de D. Domingo Fontán, grabada en 1845, que pone en este sitio de PONTE-CESO el paso del río, por un puente, comunicando los caminos que, por el N., iban a Corme o a Malpica o a Buño y, por el S., hacia Laxe y Camariñas. Carré Aldao nos asegura que era un "antiguo puente romano... muy hermoso y de piedra", que "por su estado ruinoso y de abandono fue substituido por el actual"3. . El sello municipal de PONTECESO que figura en la Geografía General del Reino de Galicia, representa, bajo el escudo antiguo de España encimado por la corona real, un puente de seis arcos que querrá evocar o simbolizar el que precedió al de nuestros días ${ }^{4}$. Ignoramos la época en que se creó este sello, que no se pretende, por tanto, esgrimir como dato documental.

El puente de 1845 era, sin duda, el que por aquellos mismos años (1845-1848), habrá atravesado muchas veces el joven Eduardo Pondal en

\footnotetext{
${ }^{3}$ CARRÉ AlDAO, E., Geografía General del Reino de Galicia, provincia de La Coruña, ed. Carreras y Candi, t. II, s.a., p. 204.

${ }^{4}$ Op. et. vol. cit. en mi nota anterior, p. 194. 
sus cabalgadas de escolar hacia la preceptoría de Nemiña ${ }^{5}$.

Los caminos que se señalaron arriba eran, por otra parte, de origen romano, como lo demuestra, amén de otras pruebas, el topónimo Meixoada $<{ }^{*} \mathrm{~m}$ a $\mathrm{n} \mathrm{s}$ i o $\mathrm{n} \overline{\mathrm{a}} \mathrm{t}$ a, en la vecina parroquia de CESULLAS, en el municipio de CABANA.

Es sabido que el género gramatical del galaico-portugués ponte y del ant. castell. puente (la puente) es femenino ${ }^{6}$. Compárense, en toponimia gallega, los Ponte Pequena, Ponte Gorda, Ponte Vella, Ponte Nova, Ponte Ferreira, Ponte Cepeira, Ponte Retorta, Ponte Pedriña, Pontevedra. Y el mismo trato fue siempre el de PONTE-CESO, como nos lo confirma, desde el siglo pasado, su mención frecuente en Pondal:

Campana, se polo vran ves lumiar na Ponte-Ceso a cachela de San Xoán...?

Eu nacín na pequena Ponte-Ceso... ${ }^{8}$

O mariñeiro que está na Ponte-Ceso atracado... ${ }^{9}$

Pasei pola Ponte-Ceso cheo de ansia e de temor... ${ }^{10}$

Se non for na Ponte-Ceso sepultádeme na Cruña... ${ }^{11}$

\footnotetext{
${ }^{5}$ PONDAL, E., Queixumes dos pinos e outros poemas, ed. Castrelos, Vigo, 1970. Léase, por ejemplo, O dolmen de Dombate (pp. 130-131) o Cando eu era inda rapás..., en pp. 180-181.

${ }^{6}$ COROMINAS, J., Diccionario crítico etimológico de la lengua castellana, t. III, 1954, p. 906.

${ }^{7}$ PONDAL, E., ed. cit. p. 106: en la versión corta de E tí campana de Anllóns..

${ }^{8}$ PONDAL, E., ed. cit. p. 141: en el poema Ponteceso.

${ }^{9}$ PONDAL E., ed. cit. pp. 154, 156: en la versión larga de E tí campana de Anllóns... A vuelta de la estrofa a que corresponde nuestra nota 7, que se repite en esta versión, emplea el poeta género masculino en la que le sigue: iPonte-Ceso saudoso, / lugar non mui grande e verde, / ledo, garrido e vizoso, / o que te mora é dichoso / esmorece quen te perde! Bien se ve que se vio movido PONDAL al masculino en el verso $1^{\circ}$, por darle como consonantes en el $3^{\circ}$ y $4^{\circ}$ de la quintilla a vizoso y dichoso, calificando el lugar de PonteCeso. Es una pura licencia poética.

${ }^{10}$ PONDAL, E., ed. cit. p. 164: en Volvendo de lonxes terras...

${ }^{11}$ PONDAL, E., ed. cit. p. 167, en A derradeira vontade.
}

"CUADERNOS DE ESTUDIOS GALLEGOS", Tomo XLI, Fascículo 106, Santiago 1993-94. 
Este hecho del género femenino de p o n s, p o n t e (REW ${ }^{3}$ 6649), que se encuentra tarnbién en hablas de Italia del Norte, en rético además y en rumano, asciende a trasiegos analógicos del latín vulgar y debió de estar generalizado en el de Hispania ${ }^{12}$.

Basta y sobra con este argumento, aunque existan otros, para rehusar todo crédito a la supuesta etimología de PONTE-CESO como venido de *p o n t e (m) c a e $\mathrm{s} \mathrm{u}(\mathrm{m})$ "puente cortado o roto". Es cierto que se encuentran en gallego derivados vulgares, casi desconocidos en otras lenguas románicas, del latín c a e d ĕ r e "cortar"13, como es de admitir que lo sea Viceso <*v i a e c a e s u m "interrupción o corte de la vía", en que se emplearía c a e s u m con valor sustantivado y con rección sintáctica y en que las circunstancias del sitio parecen apoyar la imposición ${ }^{14}$, y lo es, evidentemente, Pena Cesa, nombre de un "enorme y exento monolito", no alejado de la villa y puerto de Bares ${ }^{15}$, topónimo en que está c a e $\mathrm{s}$ a como puro adjetivo y en la esperada concordancia.

Pero diverso de ambos sería el caso de PONTE-CESO. A esta dificultad gramatical se juntaría aquí la de la significación extraña. ¿Qué denotaría en este caso el calificativo? ¿Un puente levadizo, abatible o de tablas, en algún tramo de su longitud, y esto desde la etapa de construcción, de que debería provenir el nombre? ¿O alguna rara apariencia de la fábrica de piedra del puente, que la asemejase a rotura o corte?

Por los motivos que expongo, me inclino a creer que el verdadero

${ }^{12}$ MEYER-LÜBKE, W., Grammaire des Langues Romanes, reed. de la tr. franc., 1923, t. II, \&378, p. 469. La analogía arrastró, sin duda, a los masculinos f o n s y p o n s, cuyas terminaciones consonaban con la de f r o n s, al género femenino que era el de esta voz. De ahí, en gall. o port. a fonte, a ponte como a fronte, o los demás paralelos hispánicos.

${ }^{13}$ En su REW ${ }^{3}$ no da entrada MEYER-LÜBKE a otros directos derivados que, bajo el $\mathrm{n}^{\circ} 1462$, a los del sustantivo $\mathrm{c}$ a e d e s y, en el $\mathrm{n}^{\circ} 1463$, a los de una base $* \mathrm{c}$ a e d i t a.

${ }^{14}$ Santa María de Viceso, parroquia del antiguo ay. de Brión, y p.j. de Santiago, prov. Coruña, conservaba en las cercanías del lugar de Ombre, a orillas del Tambre, restos de una vía antigua que, procedente de San Xulián de Luaña, llegaba a Santa María de Ons, iglesia filial de la de Viceso. Se señalan otros vestigios del paso sobre el río. En documentos medievales la parroquia es denominada viae cessum (sic). (Cfr. CARRÉ ALDAO, Geografía General del Reino de Galicia: provincia de La Coruña, II, pp. 481-482).

${ }^{15}$ MACIÑEIRA, F., Bares, Puerto hispánico de la primitiva navegación occidental, 1947, pp. 152,163

"CUADERNOS DE ESTUDIOS GALLEGOS", Tomo XLI, Fascículo 106, Santiago 1993-94. 
origen de PONTE-CESO es similar al que intuyó felizmente para PONTE-CESURES nuestro admirado y malogrado amigo Jesús Ferro Couselo.

Estas denominaciones, y algunas otras análogas de Galicia y Portugal, aluden al pago de algún portorium "censo, tributo, arbitrio aduanero" -mucho menos probable, de un "pontaje"-, al cruzar, sobre dichos puentes, ríos que separaban distintos territorios étnicos o distritos fiscales. Si esta práctica proseguía entre nosotros, como lo creo muy verosímil, alguna institución indígena ${ }^{16}$, o se trata de una innovación introducida por la fiscalidad romana ${ }^{17}$, es cuestión ajena a este lugar. El río Anllóns marcaba, casi de seguro, al menos en este tramo final de su curso, la linde meridional de los Brigantini ${ }^{18}$.

PONTE-CESO provendrá, últimamente, de * p o n t e (m) a d c e ns u (m) o de *p o n t e (m) d e c e n s u, así como PONTE-CESURES de *p o n t e (m) d e c e n s u r i s. La eliminación o temprana absorción fonética tras vocal (ya extinguida la $-m$ ), de las preposiciones proclíticas

${ }^{16}$ Sería institución similar, o idéntica, a la que César nos da a conocer entre los celtas de la Galia, refiriéndose a las fuentes de la riqueza del magnate heduo Dumnorix: compluris annos $p$ o $r$ t o $r$ i a reliquaque omnia Haeduorum vectigalia parvo pretio redempta habere... (BG I 18).

Las tribus alpinas sometían a los mercaderes, fuesen romanos o no, a tasas de importación subidas: causa mittendi <legionen XII> fuit quod iter per Alpes, quo magno cum periculo magnisque cum por to ri is mercatores ire consuerant, patefieri volebat (BG III 1).

${ }^{17}$ SMITH, W., A Dictionary of Greek and Roman Antiquities ${ }^{3}, 1867$, s.v. Portorium, pp. 794-795: "... sometimes... the name portorium is also applied to the duties raised upon goods for being carried through a country or over bridges..." DAREMBERG-SAGLIO, Dict. des Antiq., IV, s.v. Portorium, p. 586 ss. Bibliografía posterior se aduce por ROSTOVSEV, M., Storia economica e sociale dell'impero romano, ed. ital., pp. 188-190, n. 23.

${ }^{18}$ Los Brigantini constituían, sin duda, una subagrupación de los Artabri (LÓPEZ CUEVILLAS, F., La civilización céltica en Galicia, 1953, p. 51). Su territorio comprendía el del actual Bergantiños, cuyo centro está hoy en la villa de Carballo, e incluia entonces, a lo que infiero, las parroquias a la margen derecha del río, en A Ribeira de Anllóns.

Al Sur de esta linde fluvial se extiende hoy la tierra de Soneira, corónimo que se ha interpretado, con pleno acierto, como s u b - n e r i a, esto es, comarca sita bajo la de los $\mathrm{N}$ e r i i o Nerios. Quedarían estos últimos, por consiguiente, al NO de Soneira y confinaban, por su límite oriental, con los Brigantini.

Es muy orientador el reparto de las parroquias en comarcas tradicionales que presentó un buen conocedor de este país y de su documentación, ROMERO LEMA, F., en La lengua de Cristóbal Colón, La Coruña, 1969, p. 18, nº 36.

"CUADERNOS DE ESTUDIOS GALLEGOS", Tomo XLI, Fascículo 106, Santiago 1993-94. 
dentro de un grupo léxico y acentual, es del todo explicable. Restos de tales preposiciones subsisten, para asegurarnos de su presencia, en pronunciaciones registradas aún hoy del tipo de Ponte-a-Pedre (*p o n te (m) a d petrae $<1$ o c u m $>)^{19}$ y ${ }^{19 a}$.

No doy aún por indiscutible, si bien lo tengo por lo más probable, que esta etimología explique de rechazo, y sea corroborada a la vez, por la de CESULLAS, feligresía a que pertenece el lugar de PONTE-CESO en la banda Sur del Anllóns, al que ya me he referido. Vendría de *c e n s uc (u) 1 a s, formación diminutiva sobre c e n s u s "tasa, impuesto" (REW ${ }^{3}$ 1809).

La adquisición por este nombre latino del valor semántico de "tributo, arbitrio, tasa", al menos desde el latín tardío ${ }^{19 b}$, lo evidencia asimis-

\footnotetext{
${ }^{19}$ Es pronunciación escuchada personalmente por mí en este lugar. Su étimo no es el genitivo Petri del nombre personal Petrus, sino el genitivo petra e del sustantivo p e t r a "roca", que pasó frecuentemente en el mundo romano a designación toponímica. La aplicación se justifica aquí porque la aldea, muy ancestral, inmediata al puente, esparce sus viviendas, en que predomina la piedra, sobre los peñascos de un roquedo natural.

En los escritos del P. Sarmiento figuran testimonios suyos que nos aseguran de esta forma de pronunciación en el siglo XVIII; así, en concreto, la oyó en Ponte-a-Valga, como se puede leer en el Catálogo de voces y frases de la lengua gallega, ed. de JOSÉ L. PENSADO, Salamanca, 1973, p. 406.

${ }^{19 a}$ Estimo hoy más probable que el sintagma originador de PONTE-CESO haya consistido en *p on t e de ce n s u y no en *p on te ad cen su m. Habrá ocurrido en aquel la pérdida de la $-d$ - intervocálica y, luego, la mera simplificación de $e-e>e$.

Nos da esto también mejor razón de Pontecesures como venido de *p o n t e d e c e ns u r i s y no de *p on te a ce n s u ris, pues aparte de la menor comprensibilidad de un uso de ablativo de separación u origen en esta expresión, no tengo noticia de que ni en Ponteceso ni en Pontecesures se haya percibido jamás el menor rastro fonético de una $a$ preexistente, por contraste con Ponte- $a$-Vea (<* p o n t e a d vi a m), escuchado por mí allí mismo hace más de tres décadas, o con Ponte-a-Valga (<*p o n t e a d v a ll i c a m), oído por el P. Sarmiento en el siglo XVIII.

Debiera ser superfluo recordar aquí la noción trivial, aunque su olvido impulsó un día a un objetante categórico contra el étimo por mí dado, de que el grupo latino -ns- entre vocales se redujo a - $s$ - no sólo en época arcaica (tipo c o n s u l > c o s u l), sino, a partir de ella, en todo el decurso del latín vulgar que acredita nuestro romance: m e n s a $>$ mesa, p e n s u m > peso, t e n s u m > teso, d e f e n s a > devesa, etc., etc., etc. (MENÉNDEZ PIDAL, Manual10, 1958, \&47 a, pp. 136-137).

${ }^{196}$ No desde "el latín tardío", sino ya en el de comienzos del siglo I, debo ahora afirmar la vigencia semántica del latín c e n s u s "tributo, tasa". Así se encuentra ya transmitida, voz y significación, en el griego de la koiné, y en los dominios más apartados del Imperio

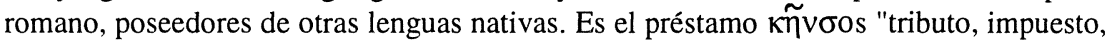

"CUADERNOS DE ESTUDIOS GALLEGOS", Tomo XLI, Fascículo 106, Santiago 1993-94. 
mo el rético tscheins o el vocablo alemán Zins "canon, foro, renta, pecho, tributo"20.

De una escritura de Fernando II, documento de donación que se hizo en Junio de 1175 a favor del monasterio de Sobrado, se ha querido deducir que PONTE-CESO habría tomado su nombre del del río, el cual aparecería en el diploma escrito Decesso, y que así se llamaba o bien Cesso, e incluso que se le conocería como Ceso en nuestros días. Este conjunto de afirmaciones se basa, evidentemente, en una interpretación errónea ${ }^{21}$. El documento aludido sólo se nos conservó en una copia, la del Tumbo de Sobrado ${ }^{22}$, copia que es defectuosa y que, lejos de atestiguar tan singular potamónimo, brinda elementos para que, en sana crítica, podamos restituir en el lugar deturpado una mención de PONTE-CESO en época medieval, quizás la primera de cuantas nos hayan llegado.

Delimita así esta escritura los términos de las iglesias donadas:

"...ego domnus Fernandus... una cum filio meo rege domno Adefonso, do... illas ecclesias, scilicet, de Armerezo et de Curispineto, et do eas uobis per tales terminos, scilicet per mediam uenam fluminis de Decesso (sic) et per iuncale de Telia et inde per locum quo diuiditur hereditates uille Telie et uille Lestimonii et inde per Moagiouet per Meytuphi et inde per Blantones et indeque per Corme et per montem Uirdidum sicut intrat in mare..." ${ }^{23}$.

La superposición $d e+D e$ en la cláusula "per mediam uenam fluminis de Decesso" es indicio de haber sido mal interpretada y deformada, seguramente por el copista del Tumbo, la mención de nuestro topónimo en el original, en que Ponte figuraría escrito mediante abreviación por $P e$ o Pte,

gabela" lo que aparece, para nombrar una carga fiscal, en inscripciones y papiros de las provincias romanas de Asia, pero sobre todo, muy determinadamente, en tres pasajes evangélicos: Mc 12, 14; Mt 17, 25 y 22, 19. El tercer evangelista, con un nivel de lengua más puro y menos popular, retiene el término propio del griego: $\varphi$ ópos (Lc 20, 22). Cfr. BLASSDEBRUNNER, Grammatik d. neut. Griechisch ${ }^{8}$, 1949, pp. 5-6

La época de estos escritos neotestamentarios que coincide con la del apoderamiento romanizador intenso del NO hispano, que se procede a surcar de vías enlazadas por puentes, es lógico que haya sido coetánea de la primera aplicación de c e n s u s y sus relacionados a los mismos parajes en que los registramos ahora.

${ }^{20}$ KLUGE, F., Etymol. Wörterb, d. deutschen Sprache $e^{20}, 1967$, p. 885.

${ }^{21}$ CARRÉ ALDAO, E., op. cit. en nuestras notas 3, 4, 14; t. II, p. 204.

${ }^{22}$ LOSCERTALES DE G. DE VALDEAVELLANO, P., Tumbos del monasterio de Sobrado de los Monjes, II, 1976, Dto. 33, pp. 58-59.

${ }^{23} \mathrm{Op}$. et loc. cit. en nuestra nota anterior, p. 58.

"CUADERNOS DE eSTUdios GALLEGOS", Tomo XLI, Fascículo 106, Santiago 1993-94. 
acaso con alguna tilde o signo diacrítico para la vocal y nasal omitidas. Esto nos devolvería la expresión correcta: "scilicet per mediam uenam fluminis de $P$ (ont)ecesso et per iuncale de Telia...", alejándose con ello el fantasma del supuesto río Ceso o Deceso, imaginado exclusivamente en base a la lección estropeada del Tumbo de Sobrado ${ }^{23 a}$.

\section{Allones / Anllóns}

Es obligado eliminar cuanto antes, en la mención de la parroquia y de los lugares homónimos $(=101,102)$ y en la del río, del que se supone que tomaron su designación los primeros, el barbarismo castrápico ALLONES (véase arriba, $I, 4^{\circ}$ ). No representa ni una solución castellana (le correspondería *Anjones) ni la gallega, que es la única legítima: ANLLÓNS.

Los testimonios orales y escritos, entrando en cuenta, en su recta valoración, las latinizaciones medievales, y los datos objetivos de obser-

\footnotetext{
${ }^{23 a}$ No se sabe hoy del original de esta escritura, como en el informe de 1979 había ya afirmado y se seguía de su falta de mención en los Documentos Reales de SÁNCHEZ BELDA, n 369 , pp. 367-368 o en la Regesta de J. GONZÁLEZ, p. 441. Pero agradezco ahora al Director del AHG, don Pedro López, y a doña Mar García, información, con sendas fotocopias, de dos traslados notariales realizados, respectivamente, el 16-VII-1502 y el 28-XI-1559, y contenidos en un apeo de la jurisdicción de Almerezo efectuado a pedimento del monasterio de Sobrado (Archivo Histórico del Reino de Galicia, Col. Docum. de C. Vaamonde Lores, caja $\left.6(1), n^{\circ} 7\right)$.

El traslado de 1502 concuerda bastante fielmente con la transcripción de la escritura en la ed. del Tumbo por P. LOSCERTALES. Las voces discutidas se reproducen así: "fluminis de decesso".

En el del año 1559 la preposición de se intercaló, alzándola algo sobre el renglón, en el angosto espacio que había quedado entre las otras dos voces copiadas antes: "fluminis de cesso".

Puede todo ello ser prueba, y con esto modifico algo mi hipótesis de 1979, de que en 1175 , época del diploma original, no se decía el antiguo y propio nombre del río, que ignoramos todavía hoy, tras el sustantivo p o $\mathrm{n}$ e, al que nunca habrá seguido la mención del potamónimo, pero sí subsistía en la pronunciación local de la preposición de, eliminada ya la $(d)$, una mera - $e$ en vías de pérdida: p o n t e e c e s s o.

El escriba del diploma de 1175 supuso ser e c e s s o el nombre del f l u m e n, y así lo habrá reproducido, prescindiendo de p o n t e: "fluminis e cesso".

El copista de 1502 suplió la (d) desaparecida y conjeturó tomándola -"avant la lettre"por enmienda de una inexistente ditografía, que era igual partícula la eliminada en Decesso, que restituyó como nombre del río.

El copista de 1559, más apegado al tenor del diploma original o de una fiel copia suya, se contentó con anteponer una $(d)$ a la aislada e incomprensible $e$ que leía en su modelo.
}

"CUADERNOS DE ESTUDIOS GALLEGOS", Tomo XLI, Fascículo 106, Santiago 1993-94. 
vación topográfica, nos dan absoluta seguridad no ya sólo de lo fundado de esta rectificación, sino, incluso, de la del étimo asignado certeramente por don Abelardo Moralejo a esta voz geográfica: * a n g u 1 ō n e s, esto es, "grandes ángulos", zigzags o inflexiones". Así hubieron de ser designadas desde época romana las curvas que el río, en forma de dos meandros amplísimos, describe en la parte de su curso que abraza términos de la parroquia de ANLLÓNS, a vista de PONTE-CESO ${ }^{24}$.

La base etimológica propuesta por Moralejo se justifica, en efecto, por este curso final. La entrada en el primero de los meandros la realiza por el paraje conocido como A Chousa dos Anllóns, subiendo el río de S. o NO. y alcanzando un punto máximo por el lugar de A SAÍMIA. Desde aquí, baja de N. a S., pasando por el lugar y puente de A GARGA; tuerce al E. bordeando A Ribeira y, a poco, asciende otra vez al N. para bañar por el S. PONTE-CESO, en su marcha ya definitiva, rumbo E.-SE., cara al estuario y a la ría ${ }^{25}$.

Es de observar que el topónimo Chousa (<c l a u s a) dos Anllóns, en el comienzo de la primera inflexión, apartado de ANLLÓNS GRANDE y ANLLÓNS DE ARRIBA, que se incluye en la bolsa encerrada en la segunda inflexión, prueba cómo * a n g u 1 ō n e s o *anllóns era, al principio, apelativo común en plural de ambos meandros fluviales y no, propiamente, topónimo ni potamónimo.

En el aspecto lingüístico los topónimos de la misma familia, Anllo (<a n g ŭ l u m), Anllada (<a n g u 1 à t a), o el sustantivo común anllar o unllar "rincón para la leña junto a la lareira" (<a n g u 1 ā r e), corroboran el origen y sentido primario de nuestro Anllóns ${ }^{26}$.

Las pseudo-latinizaciones del siglo XII, Allionis o Alliones, con las que se nombra a la parroquia ${ }^{27}$, lo único que manifiestan es la dificultad

\footnotetext{
${ }^{24}$ MORALEJO LASSO, A., Toponimia gallega y leonesa, 1977, pp. 243, 255 n. 26, 313.

${ }^{25}$ Me baso en múltiple documentación cartográfica, pero, principalmente, en la Hoja 43 del 1/50.000 y en la Hoja 15 del 1/25.000, del Instituto Geográfico y Catastral.

${ }^{26}$ Anllo fue citado ya oportunamente por MORALEJO, op. cit., pp. 243 y 255 n. 26. Anllada (=icruce o recodo de caminos?) es nombre de un lugar de San Bréixome de Arcos, ay. Cuntis, Pontevedra (ÁLVAREZ LIMESES, G., Geogr. Genr. del Reino de Galicia: Prov. de Pontevedra, p. 391). Para anllar, unllar etc., véase RODRÍGUEZ GONZÁLEZ, Dicc. encicl. gallego castellano, t. I, 1958, p. 177.

${ }^{27}$ Allionis se lee en el original del documento de donación de Fernando II al monasterio de Sobrado, de 29 de junio de 1178: unum seruicialem in Allionis (SÁNCHEZ BELDA, L., Documentos reales de la Edad Media referentes a Galicia, Madrid, 1953, $\mathrm{n}^{\circ} 381$, p. 179).
} 
que experimentaban ya los escribas o datantes para rescatar el étimo, pero responden a una pronunciación viva igual, o no muy distante, de la forma gallega correcta actual, inmortalizada en las citaciones poéticas de Eduardo Pondal ${ }^{28}$.

Puesto que primitivamente *anllóns "grandes recodos o meandros del río" no era otra cosa que una designación descriptiva romana de un aspecto del mismo en su curso último, se plantea desde aquí la incógnita del nombre prerromano de esta considerable corriente fluvial. Es bastante común que estas denominaciones primitivas no se hayan desvanecido del todo, sino que, en ocasiones, se enmascaren tras algún topónimo de parajes de sus riberas. Hay una lejana posibilidad, en este caso, de quie tenga solución latente en la voz geográfica, hoy topónimo, A SAÍMIA ${ }^{28 a}$.

\section{Garga / A Garga}

Advierto desde aquí, una vez por todas, que la anteposición potestativa del artículo determinado (que denoto en bastantes de estos topónimos poniendo entre paréntesis, a continuación de ellos, la forma correspondiente), no persigue tanto el que se los consigne así en el Nomenclator oficial —que tiende, por lo general, a prescindir de elementos extrínsecos al puro nombre propio - como el de recomendarla, por si así se acepta, para la señalización municipal, ya que, en los casos en que la registro, he podido comprobar la integración usualísima, por los hablantes nativos, de los artículos en la mención de tales lugares.

Los letreros o placas en que figurasen contribuirían en forma indirecta, por consiguiente, a la finalidad educativa del mejor ajuste entre las peculiaridades constructivas de la lengua tradicional y los rótulos administrativos que las reflejan.

\footnotetext{
Alliones está en dos copias del diploma de confirmación al mismo monasterio otorgado por don Alfonso IX, el 10 de Noviembre de 1189. Véase más adelante el extracto en el cuerpo de este dictamen: 400 CORME-ALDEA.

${ }^{28}$ PONDAL, E., ed. cit., pp. 54, 87, 105, 141, 156, 159 y 181.

${ }^{28 \mathrm{~A}} \mathrm{Al}$ añadir esta nota en 1994 creo muy improbable la posibilidad, a que me inclinaba en 1979, de que A SAÍMIA, que habrá denominado a un manantial, de aguas termales vercsímilmente, en el curso ya muy avanzado del río, pueda haber servido para nombre por el que se reconociese a todo este, o en su mayor parte. Se trata, además, de una voz latina, y de todos los grandes ríos de Galicia suele saberse su denominación prerromana, o que al menos la tuvieron para toda o la más extensa parte de su recorrido. Me abstengo aún de intentar esta búsqueda del primitivo potamónimo.
}

"CUADERNOS DE ESTUDIOS GALLEGOS", Tomo XLI, Fascículo 106, Santiago 1993-94. 
El lugar de A GARGA, sito en una zona algo deprimida cuyo contorno recibe nombre también de $A$ Bardanca, está presidido por un puente de dos arcos (ponte da Garga o ponte de Anllóns), muy antiguo y presumo que romano en su origen, pero rehecho. Enlazaba con un camino viejo y profundo, entre "carballos", enlosado aún hace pocos años de losas de "piedra morceña", calidad de material que se encuentra, según mi acompañante el prof. Suárez Cotelo, en TALLO.

Pertenece GARGA, por su étimo, a la familia del castell. y gall.portugués garganta, en la acepción de "estrechamiento de una montaña, río, valle", lo que conviene a este sitio. Los sonidos y sentidos de las palabras de su grupo se entrecruzaron con la prole del latín vulgar g u r g a que, con los significados de "remolino, vórtice o pozo de río", admitió también el de "garganta humaną o de un monte"29.

Sin pretender abordar aquí su estudio, baste con referirnos a algunos emparentados de una u otra familia en nuestra toponimia gallega, o a resultados de la combinación de ambas: Garga, Garganta, Gargamala, Gargalo, Galgueira, Gargantáns, Gargantós; o bien, por otra parte, Gorga, Gorgal, Gorgueira, Golgueira, Gorgueiro.

\section{Saimia / A Saímia}

Es de todo punto necesario, en la notación de los topónimos, que en los rótulos en que se utilicen capitales no se deje de poner, en previsión de una duda fundada, acento gráfico sobre aquellas formas que, de lo contrario, se prestarían a lectura equivocada. En la pronunciación popular de esta voz - anotada por mí directamente- el hiato permanece aún sin resolver entre las dos primeras vocales de ella y debe señalárselo con el acento diacrítico.

No existe, que sepamos, paralelo exacto de esta palabra en la toponimia gallega oficial. De su presente contextura parece deducirse, sin el menor esfuerzo, una base antigua: ${ }^{*} \mathrm{~s}$ a $1 \overline{1} \mathrm{~m} \breve{\mathrm{n}}$ a. Problema diverso es el de su interpretación etimológica. Dejo sugeridas aquí las tres hipótesis que he creído más viables, pero entre las que me inclino, preferentemente, a la primera de ellas, sin que revista tal terminante certeza que nos fuerce ya a denegar algún grado de posibilidad a las que enuncio después:

${ }^{29} \mathrm{REW} 3,3921$, g u r g a. Véase GARCÍA DE DIEGO, V., Contribución al Diccionario hispánico etimológico, Madrid, 1943, nº 291, p. 93.

"CUADERNOS DE ESTUDIOS GALLEGOS", Tomo XLI, Fascículo 106, Santiago 1993-94. 
a) Relación con el verbo s a 1 īr e "brotar" (REW $\left.{ }^{3} 7540\right)$, aludiendo a la cercanía de algún manantial o surgimiento de aguas, termales por ejemplo. Es lo cierto que en la Hoja 43 del 1/50.000 se consigna al lado de A SAÍMIA un paraje que se llama Caldas.

Juzgo muy verosímil, en el supuesto de esta conexión, que también la tenga A SAÍMIA con el topónimo asturiano Salime, pueblecito desaparecido bajo las aguas del gran embalse del Navia, en el municipio de Grandas de Salime, p.j. Castropol y prov. Oviedo. Según el informante de Madoz, se caracterizaba este término, ribereño del río Navia, por su abundancia en fuentes y manantiales ${ }^{30}$.

La base * s a $1 \overline{1} \mathrm{~m}$ e $\mathrm{n}$, en singular, confirmaría la base en plural * s a $1 \overline{1} \mathrm{~m}$ ĭ a, que está tras A SAÍMIA.

Aquella base * s a 1 īm e n se vuelve a hallar, en mi opinión, en el topónimo Saíme - de Arriba y de Abaixo - de un lugar de San Julián de Bastabales, ay. Brión, prov. Coruña, parroquia en que hay "abundancia de fuentes naturales"31, y en otro Saíme todavía, de la fel. de Santa María de Librán, ay. Baleira, p.j. Fonsagrada, prov. Lugo ${ }^{32}$.

Tiene evidente parentesco con estas voces la de Saidoiro (<*s a 1 it o r i u m), que nombra a un manantial del lugar de Troncoso, en la fel. y ay. de Mondariz, y a un riachuelo, afluente del Oitavén, en la fel. de San Lorenzo de Fornelos de Montes, ambos en la prov. de Pontevedra ${ }^{33}$.

Recuerdo, por último, cómo en el Itinerarium Antonini, se nombra, en locativo, la mansión de $\mathrm{S}$ a $\mathrm{l}$ i e $\mathrm{n} \mathrm{t}$ i b u s, en la segunda ruta de BragaAstorga $(428,4)$, cuya mención retiene el Ravenate (libr. IV, cap. 42). Se sobrentiende s a li e n t i b u s <a q vis $>$.

b) Relación con sal (REW ${ }^{3}$ 7521), s a $1 \overline{1} \mathrm{n}$ a gall. saíña (REW ${ }^{3}$ 7535) etc., si es que de algún modo hacía sentir su presencia en A SAÍMIA, o se explotaba o desecaba en ella la sal marina.

\footnotetext{
${ }^{30}$ MADOZ, P., Dicc.

${ }^{31}$ CARRÉ ALDAO, E., Geogr. Gen. del Reino de Galicia: Prov. Coruña (en adelante: GG-C), t. II, p. 478.

${ }^{32}$ AMOR MEILÁN, M., Gogr. Gen. del Reino de Galicia: Prov. Lugo (en adelante: GG-L), p. 411.

${ }^{33}$ ÁLVAREZ LIMESES, G., Geogr. Gen. del Reino de Galicia: Prov. Pontevedra (en adelante: GG-P) pp. 694, 749.
}

"CUADERNOS DE ESTUDIOS GALLEGOS", Tomo XLI, Fascículo 106, Santiago 1993-94. 
c) Relación con el tema hidronímico s a 1 a de los antiguos europeos —confróntese lat. s a 1 u m "mar", ant. irl. s a 1 "idem", ant. prus. s a 1 u s "arroyo"- del cual nos ofreció Krahe una serie amplia de bases y deriva$\operatorname{dos}^{34}$. Entre ellas, S a 1 i a (de donde, en España, el santanderino Saja, el asturiano Sella, gallego Xallas, etc.), S a 1 i c a, S a $1 \mathrm{n}$ a, S a $1 \mathrm{~m}$ a n a, $\mathrm{S}$ a $1 \mathrm{~m}$ a s a, etc. ${ }^{35}$.

La adición de un morfema en -m ( $\mathrm{S}$ a $1 \mathrm{~m}$ a y otros) o en - in a (I s -i- n a, A l b-i-n a, D r a v-i-n a, S a r-i-n a, etc.) al tema, es típica del sistema hidronímico referido, pero no encuentro correspondencia para la conglutinación de ambos (esto es, - $m+$-i n a-), que se acoplaría, a lo que parece, mediante una -i- largá, con el tema precedente: S a l-i-. La hipótesis, en sí atrayente, debe quedar relegada, por el momento, a una lejana posibilidad ${ }^{35 a}$.

\section{0 (+202 - 203) Brantuas / Brantuas}

Es de étimo aún desconocido, si bien prerromano, sin duda, el nombre del "val de Brantuas" de Pondal ${ }^{36}$. Se trata del vocablo que ya en el mencionado documento de Fernando II, del año 1175, aparece pseudolatinizado como B 1 a n t o n e s.

Quizás se asocie por su tema a voces toponímicas como Brántega (San Lorenzo), feligresía rica en mámoas, del ay. de Agolada, Pontevedra ${ }^{37}$, Brancio, lugar de la fel. de Santa María de Arroxo, Fonsagrada, Lugo ${ }^{38}$, o Brazá y Branzailla, feligresía y lugar, respectivamente, del ay. de Arzúa, Coruña ${ }^{39}$.

${ }^{34}$ KRAHE, H., Die Struktur der alteuropäischen Hydronimie, en las Abhand. d. Akad. d. Wissens. und d. Liter., Mainz, 1962, pp. 291 ss. con tabla entre pp. 296-297, pp. 333335.

${ }^{35}$ Para el santanderino Saja, documento del año 978: "qui est in ripa de Salia flumine, ubi dicitur Golbardo" (véase GONZÁLEZ ECHEGARAY, J., Nueva interpretación del texto de Mela 3, 13, en Altamira, ${ }^{\circ} 1$, p. 106). Para el asturiano Sella, véase del mismo autor, El litoral asturiano en época romana, Oviedo, 1954, p. 42, nº 2. Para los morfemas o sufijos, KRAHE, art. cit.

${ }^{35}$ El carácter latino de *s a $1 \overline{1}$ m In a, base de A SAIMIA, que ya en 1979 daba por étimo preferente, así como su única localización, a lo que parece, en un punto avanzado del cauce fluvial, contribuye a verlo incapaz de constituir la solución a la incógnita pendiente.

${ }^{36}$ PONDAL, E., ed. cit. p. 81: "Nos verdexantes cómaros do Esto, / no val de Brántuas, / ou de Anxeriz, / ou nas pendentes de Corcoesto, / ou sobre o cume de Gomariz..."

${ }^{37}$ GG-P, pp. 622-623.

${ }^{38}$ GG-L, p. 397.

${ }^{39}$ GG-C, t. II, p. 16.

"CUADERNOS DE ESTUDIOS GALLEGOS", Tomo XLI, Fascículo 106, Santiago 1993-94. 


\section{Angeles / Anxeles (Os)}

Existe en este punto una capilla, según mis referencias, que motivó el desplazamiento de la advocación a topónimo.

El criterio en que se basa nuestra recomendación de grafía - condición de préstamo refrendado por la adhesión local—queda expuesto en I, $5^{\circ}$.

\section{Cores / Cores}

El presente topónimo, correspondiente a la parroquia de San Martiño de CORES, entiendo que se identifica con el que cita un documento de 7 de Mayo del año 867, dado por el obispo Rudesindo o Rosendo I de Mondoñedo, e incluido en el Tumbo de Sobrado, por el que donó bienes a la iglesia de A r m e r e t i o (Almerezo), en el territorio de B re g a $\mathrm{n} \mathrm{ti-}$ n o s (Bergantiños). Dice así el pasaje, en que excluye del contenido de la donación algunos bienes sitos en este lugar:

"Alias vero uillas meas, seu pumares et uineas, excepto quod in

Coris germanis meis omnem meam portionem concessi..." 40

Pero resulta ser este mismo sitio el que siete años antes, a 14 de Diciembre del 860, había mencionado en forma algo diversa un diploma, también recogido en el Tumbo de Sobrado:

"Proinde nobis optata et plena complacuit uoluntas ut donaremus eclesiis sanctorum martirum Dei sancti Tirsi et sancti Martini et sanctorum Iuliani et Baselise, quorum basilicas sunt fundatas in uilla que dicitur Corissumario, qui est territorio Bregantinos. Damus atque donamus ex mediatate de pumare quod est hic in Corissumario iuxta sanctum Martinum, et uillam quam obtinuir Felix que est inter Castrum et Nemenio..."41

La referencia a San Martiño de CORES es inequívoca y muy precisa. No es adscribible esta voz geográfica, CORES, a un étimo latino. Co-

${ }^{40}$ Ed. cit. en nuestra nota 22, t. I, n ${ }^{\circ} 123$, pp. 152-155; la cláusula extractada, en p. 154. Publicó también este documento LÓPEZ FERREIRO, A., Historia de la S.A.M.I. de Santiago de Compostela, t. II, 1899, Apéndice, VII, pp. 13-17.

${ }^{41} E d$. cit. en nuestra nota 22, T. I, n ${ }^{\circ} 124$, pp. 155-156. En un documento de cien años después, del 3-III-960, se cita una "villa de Corissumario", cuya identidad con la que nos ocupa, no nos paramos a puntualizar. (Véase $e$ d. cit., t. I, n ${ }^{\circ}$ 22, pp. 151-152).

${ }^{41 a}$ Puede verse ya ahora lo que resumo, respecto a cor- y sus derivados, como a los

"CUADERNOS DE ESTUDIOS GALLEGOS", Tomo XLI, Fascículo 106, Santiago 1993-94. 
rresponde, como se verá más adelante, con el primer término de composición, transformado, de COS-PINDO y, sin duda, con el de Coris-tanco, y otros topónimos gallegos que empiezan por el tema c o r. No es éste aún el momento de ahondar en su étimo o extenderme sobre sus derivados ${ }^{41 a}$.

\section{Bardayo / Bardayo}

Son varios los factores que, bien ponderados, aconsejan mantener, por el momento, la grafía que inveteradamente se viene aplicando a este topónimo.

Es el primero el hecho, observado por mí en el interrogatorio con los hablantes locales, que si bien son capaces de emitir las articulaciones diferentes de la $l l$ (l) y la $y(y)$, se muestran inhábiles para discernirlas adecuadamente. Si el fenómeno es general (lo encontré, en algún caso, unos 13 kms. al Sur, en Bayo, que algún hablante pronunciaba balo, aunque decía hacerlo con otro fonema distinto que en alo = Allo, topónimo del pueblo vecino), predominaría en la zona la carencia de contraste fonológico, sentido, entre las dos articulaciones, lo que, en mayor o menor grado, amenaza su intangibilidad fonética o gráfica. Es a lo que se deberán estas transcripciones yeísticas.

Es lo más probable, por otra parte, que BARDAYO proceda, en realidad, de * b a r d a c (u) 1 u m, formación cuyo elemento temático, cuando menos, resulta homófono de Barda (una ensenada del litoral cercano se llama da Barda) y del precomponente de Bardanca (véase arriba, en el comentario al n ${ }^{\circ}$ 103: A GARGA).

Si tuviésemos ya por segura, con la identificación plena del étimo, la de la terminación -c (u) l u m (> gall. - llo, cast. -jo), procedería que restituyésemos, sin vacilaciones, la grafía correcta, BARDALLO, proscribiendo la transcripción yeística. Pero como no se posee aún tal certeza, es lo más prudente retener la grafía "in possessione", BARDAYO, con -y(letra que, en topónimos, autoriza en algunos casos una norma de la Academia Gallega ${ }^{42}$.

\footnotetext{
testimonios toponímicos, en Toponimia del Concejo de Pontedeume y Cartas Reales de su puebla y Alfoz, Coruña, 1987, p. 171 y passim. Cfr. Indice p. 212.

${ }^{42}$ Normas ortográficas e morfolóxicas do Idioma galego, A Cruña, 1977, p. 11: "Os signos $j$ (iota), $k(\mathrm{ka}), W$ (uve dobre) e y (y grego) úsanse só en palabras alleas, aínda que o derradeiro pódese manter tamén en certos nomes propios, especialmente topónimos, que, sendo galegos, vínanse escribindo tradicionalmente con $y^{\prime \prime}$.

${ }^{43}$ GG-C, t. I, p. 765.
}

"CUADERNOS DE ESTUDIOS GALLEGOS", Tomo XLI, Fascículo 106, Santiago 1993-94. 
Se deja con esto abierto el campo para la realización fonética dúplice de la comarca de PONTE-CESO y se soslaya, por ahora, la grafía BARDAIO, en sí menos probable y que distanciaría más a esta voz tanto del presunto origen etimológico como del modo de articulación, ambivalente por insensible al contraste distintivo, que se escucha allí promiscuamente.

\section{Limiñoa / Limiñoa (A)}

Este topónimo, que asciende a una base *1 i m i n 1 o 1 a, pertenece al tema de significado hídrico, probablemente, a que asciende el griego $\lambda i ́ \mu v \eta$ "laguna" o el nombre de nuestro río Limia (J. Pokorny, IEW, I, p. 309).

Presumo que se relaciona, topográficamente, con el sinuoso curso y primitiva apelación del río que atraviesa la parroquia, conocido por río das Chancas, o Xaveira, o río de Mens o de Vaa ( $<$ v a d a), que va a morir en la ensenada o "esteiro" de Queiruga.

\section{Miraflores / Miraflores}

No estuve en el paraje mismo así denominado. Es topónimo, sin duda, o de imposición castellana primaria, o forma castellanizada, cuyo enraizamiento como tal topónimo invita a aplicarle uno de los criterios que se explican en el apartado I, $5^{\circ}$.

Hubo, en lo que es territorio de la actual provincia coruñesa, la antigua jurisdicción de Miraflores, señorío de los Condes de Lemos, cuya capitalidad residió en el pazo de Santa María de Oleiros, ay. de Oleiros ${ }^{43}$, y existe hoy una aldea o arrabal del mismo nombre en San Pedro de Muros, ay. de Muros ${ }^{44}$. También en Pontevedra, en San Ginés de Padriñán, ay. Sanxenxo, se conoce el lugar y la Torre de Miraflores, pazo en que residió don José Pardo-Bazán y Mosquera en varios años de la década 1850-186045.

El origen, acaso popular, de este espécimen toponímico (al modo y manera de Mirapeixe, Miravales, Miramontes, etc.), o acaso tardío y foráneo, no me ha cabido aún oportunidad de ponerlo en claro. Requiere compulsa documental, observación directa y contraste comparativo de las lo-

\footnotetext{
${ }^{44}$ GG-C, t. II, pp. 383, 386.

${ }^{45}$ GG-P, pp. 453-452.
}

"CUADERNOS DE ESTUdios GALLEGOS", Tomo XLI, Fascículo 106, Santiago 1993-94. 
calidades igualmente designadas ${ }^{46}$.

\section{Orada / Ourada (A)}

Se impone la rectificación que señalamos. Responde esta forma del nombre del lugar, puesto en una elevación del terreno, a la pronunciación del pueblo, constante, a testimonios cartográficos más que centenarios (verbigracia, así está en la Carta de don Domingo Fontán, de 1845), y, sobre todo a su etimología, a u r a t a "áurea o aurífera", sobrentendiéndose t e r r a o *mo n t a n e a, o algún sustantivo femenino análogo.

Se explica la denominación por la zona de explotación aurífera en que aparece incluida A OURADA y de la que restan pruebas en la realidad minera y en los vestigios toponímicos, vgr. un Montefurado, así como arqueológico, en la dirección de SERGUDE y Santa María de Corcoesto, a $4 / 5 \mathrm{kms}$. hacia el Sur.

\section{Ríotorto / Río-Torto}

El empleo del guión separador para grupos léxicos en los que sea aún viva la distinción de elementos con un valor individualizado de significación, la entiendo aconsejable.

\section{Vilasuso / Viladesuso}

Es obligado rectificar aquí la mención en el Nomenclator, ya que en boca de los nativos de CORES, cuando no se expresan influidos momentáneamente por la forma oficial, el nombre de su lugar es VILADEDUSO y no VILASUSO, según los interrogatorios que me fue dado realizar y, para este caso, ampliar y confirmar por referentes fidedignos.

Distinta es la forma oída para el lugar de TALLO, que presento más abajo, que los vecinos llaman VILASUSO y no VILADESUSO.

Posee justificación propia cada una de ellas. La base etimológica de VILADESUSO es v i 11 a de s u (r) s u m "granja de arriba", mientras que la de VILASUSO es v i 11 a a d su (r) s u m "granja puesta en alto o

\footnotetext{
${ }^{46}$ Mirapeixe, en la ribera izquierda del Miño, asomado en efecto a sus aguas, es nombre del viejo solar y pazo de los Gayoso, en la feligresía de Santa Mariña de Rábade, ay. Otero de Rei, Lugo (GG-L, p. 271); Miravales lo es de un lugar de San Lorenzo de Sasdónigas, ay. Mondoñedo, Lugo (GG-L, p. 442) y Miramontes es topónimo al N de Santiago, junto al Tambre, y también apellido.

Cfr. otras voces geográficas recogidas por MORALEJO, A., op. cit. en nuestra nota 24: p. 339.
}

"CUADERNOS DE ESTUDIOS GALLEGOS", Tomo XLI, Fascículo 106, Santiago 1993-94. 
hacia lo alto". El significado es equivalente.

En el último topónimo la preposición a d quedó absorbida por la -a final de v i 11 a, y así se explica el acoplamiento al sustantivo femenino del poscomponente, que no es un adjetivo sino un adverbio invariable.

Por otra parte, los términos castellanos asuso < a d s u r s u m y ayuso < a d j u s u m -clásico d e o r s u m-, son otro dato que hace postular un frecuente nexo con la misma preposición desde el latín vulgar hispano.

\section{Corme-Aldea / Corme-Aldea}

Se la encuentra ya como feligresía, en forma igual a la moderna, CORME, en documentos de Fernando II, de 29 de Junio de 1178, y de Alfonso IX, de 10 de Noviembre de 1189. Este último es confirmación del primero y expresa así el contenido de las donaciones hechas al monasterio de Sobrado:

"... et in terra de Selagia ecclesiam de Ermerezo et ecclesiam de Corispenido cum cautis suis et cum toto regalengo quod est in ipsis feligresiis, et ecclesiam de Corme, et ecclesiam de Cesulles et infantaticum de Neanio quod este in terra de Sonaria, et unam servicialiam in Alliones cum omnibus directuris et pertinentiis suis..."46bis

\section{Froján / Froxán}

La adopción de la grafía $x$ para las varias realizaciones del fonema prepalatal fricativo sordo del gallego actual, en todos los casos en que se dé, está acorde con la postura que hemos justificado en el apartado I, $3^{\circ}$.

En el nombre de este lugar de CORME, evocado más de una vez por Eduardo Pondal ${ }^{47}$, se tiene el genitivo de posesor de un antropónimo hispano-gótico, Fr o j a / F r o y a, otra forma de Fro i $1 \mathrm{a}^{48}$.

46bis GONZÁLEZ, J., Alfonso IX, t. II, 1944, nº 31, pp. 54-55.

${ }^{47}$ Ed. cit., p. 48: "Amado dos nobres celtas, / vello pinal de Froxán, / os teus arbres, xa encurvados, / o vento fai rebramar..."

Apostrofa así, en otro lugar, a la lengua de Breogán: "...tí de celta ós ouvidos / sempre soando estás / como soan os pinos / na costa de Froxán..." (p. 124)

Imagina en otro poema que a "unha fada garrida / eu ben a oin cantar / de Gandomil na costa, / non lonxe de Froxán..." (p. 205).

${ }^{48}$ PIEL, J.M. - KREMER, D., Hispano-gotisches Namenbuch, Heidelberg, 1976, p. 138.

"CUADERNOS DE ESTUDIOS GALLEGOS", Tomo XLI, Fascículo 106, Santiago 1993-94. 
Verosímilmente nos conserva este sitio el recuerdo de alguno de los primitivos señores de Traba, tronco de la Casa de Altamira. En el año 1080, don Pedro Froilaz, el famoso Conde de Traba y de Caamouco, hizo una donación en las cercanías al monasterio de NEMEÑO, a la que nos referiremos más abajo.

\section{Gondomil / Gondomil}

Otro genitivo antroponímico de origen germánico: Gu n de $\mathrm{m}$ i r $\mathrm{i}^{49}$.

\section{Gujín / Guxín}

Tercer testimonio en esta parroquia de un antropónimo de "possessor" de origen hispano-gótico: es su base * G o g i n u s ${ }^{50}$.

\section{Roncudo / Roncudo (O)}

Hermoso y recio topónimo que designa al mar, personificándolo, y evocando su bronco mugir en la costa de CORME, cuyo extremo meridional es A Punta do Roncudo, y hacia la mitad de la cual se apiña el caserío de la aldea de este mismo nombre: O RONCUDO.

\section{0-501 Corme-Puerto / Corme-Porto}

Sin perjuicio de poder duplicar, en la señalización municipal, los letreros para aquellos insólitos visitantes a quienes pudiese resultar incomprensible el término gall. y port. porto -más cercano que el castell. puerto a los resultados románicos: ital. porto, franc. o prov. port, o préstamo en ingl. port-, es ya momento maduro para introducir tal modificación en el Nomenclator oficial.

La imposición de este sobrenombre distintivo fue, en principio, moderna y castellana, por vía administrativa, pero la conciencia y hábitos lingüísticos de los hablantes incorporarán al punto la forma correspondiente y usual en la lengua que les es más natural y propia.

\footnotetext{
${ }^{49}$ PIEL, J.M. - KREMER, D., op. cit. en mi nota anterior, p. 165. Un verso citado en nuestra nota 47 parece indicio de una realización fonética Gandomil, distante del étimo. No dudo que exista, a juzgar por alófonos encontrados de otras voces (vgr. de LANGUEIRÓN, pero de este nombre no los registré entre mis hablantes. PONDAL, personificando alguna vez este topónimo, escribe Gondomil. Así ed. cit. p. 138.

${ }^{50}$ PIEL, J.M. - KREMER, D., op. cit., p. 156.
}

"CUADERNOS DE ESTUDIOS GALLEGOS", Tomo XLI, Fascículo 106, Santiago 1993-94. 


\section{Observación a los topónimos a...s}

Aconsejo en todos ellos, que son mezcla de denominaciones tópicas primitivas con creaciones onomásticas recientes, surgidas al ritmo de la urbanización de la villa, que se prescinda en los rótulos municipales de anteponer el apelativo común Calle. Esta anteposición, según he observado, es desacostumbrada casi del todo en CORME en el habla popular. Se conserva, por el contrario, en algún caso —en concreto en el de RUA DOS CONDES - el antiquísimo apelativo Rúa, que podrá preferirse en su momento como nombre genérico en el callejero de la villa.

\section{g) Gafote / Gafote (O)}

Es denominación de un sitio en donde moraría algún lazarado o leproso, conocidos asimismo entre nosotros como gafos $^{51}$.

El sinónimo gafote no se encuentra en Rodríguez González, E. ${ }^{52}$, ni en otros diccionarios gallegos corsultados, pero el topónimo de CORME demuestra que existió en la lengua común. El sufijo -ote lo debe, con probabilidad, a la asociación con agote u otros términos despectivos.

\section{h) General Mourelle / General Mourelle}

Recuerda este rótulo municipal al Brigadier General de la Armada y Jefe de Escuadra Don Francisco Antonio Mourelle (1755-1820), hijo ilustre de la villa de CORME (véase Dicc. Encicl. Espasa, t. 36, p. 1481, s.v.).

Debe aplicarse aquí, a mi juicio, el criterio enunciado en el apartado I, $5^{\circ}$, puesto que esta designación en castellano del grado militar de don Francisco Antonio Mourelle, para nombrar este sitio, es común y arraiga-

${ }^{51}$ RODRIGUEZ GONZÁLEZ, E., Dicc. encicl. gall. castell., t. II, 1960, p. 393, s.v. GAFO, parece considerar la voz, en el sentido de "leproso", como término arcaico, recogido en el Vocabulario de la Crónica Troyana; pero prolongó en gallego tanto su vida cuanto persistió la lepra, con fuerte estigma social. Un nombre como Río dos Gafos, en un recodo apartado de la "veiramar" de la ciudad de Pontevedra, responde a esa persistencia.

${ }^{52} \mathrm{El}$ cruce en el topónimo local de CORME, cuya antigua imposición parece muy probable, de gafo $+<$ ag $>$ ote, plantea la probabilidad de una expansión de este último término en áreas de la Península distantes de la vasco-navarra, muy anterior a la que acreditan los textos conocidos. (Cfr. COROMINAS, J., op. cit. en mi nota 6, t. I, 1974, p. 54, $\mathrm{y}$ art. ampliado en el DCECH, t. I, 1980, pp. 74-75).

"CUADERNOS DE eSTUDIOS GALLEGOS", Tomo XLI, Fascículo 106, Santiago 1993-94. 
da entre los hablantes de CORME ${ }^{52 a}$.

\section{i) Huertas / Hortas}

Comprobé personalmente en CORME el empleo predominante de HORTAS, que es la designación antigua, para lo que fue lugar y barrio antes, y hoy es calle.

\section{j) Marina / Marina}

El nombre de marina para un "paseo o zona lindante con el mar en una población" es forma y costumbre, en nuestras villas, de origen generalmente moderno y castellano, pues que son voces como veiramar, ribeira, orela do mar (no tan usual), o análogas, las acuñadas en gallego, preferentemente, para expresar lo mismo.

Caso distinto es el de la antigua aplicación a comarcas enteras de un país muy orillado al mar o penetrado por él, del apelativo mariña, que se convirtió en Galicia, por lo común, en corónimo, como A Mariña, As Mariñas, etc.

En el caso de CORME creo recomendable, por ahora, mantener la forma tal cual se la oye. No prejuzga esto, en otro estadio de la conciencia lingüística popular, de una prescripción distinta. Porque puede, en cierto modo, asimilarse el castellanismo MARINA a una retrogradación culta, en parecida manera a cómo, junto a adiviñar, se emplea tanto en portugués como en gallego divino, divina, divinal, etc., o destinar, destino, etc., que resultan ser el patrón latino inalterado.

Es curioso que encontremos en Eduardo Pondal muestra del doble tratamiento de esta forma que acabo de diseñar:

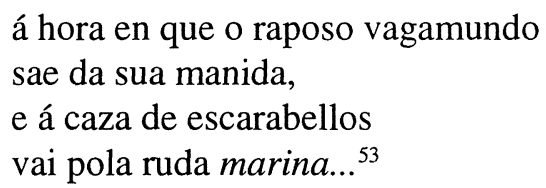

\footnotetext{
${ }^{52 a}$ El sentimiento hoy más vivo, estimulado y guiado por la enseñanza de la lengua, de las expresiones propias del gallego, favorece ya ahora la adopción de la forma gráfica Xeneral (sustantivo) contrapuesta a xeral (adjetivo).

${ }^{53}$ PONDAL, E., ed. cit., p. 63.
}

"CUADERNOS DE ESTUDIOS GALLEGOS", Tomo XLI, Fascículo 106, Santiago 1993-94. 
pero, por el contrario,

- Tí, da chaqueta vermella tua terra ditosa dime:

- O meu vestir ben o di a todos que ben me miren: do alegre chan da Mariña e doce terra de Bribes $^{54}$.

\section{k) Arnela / Arnela}

O bien A ARNELA (<*a r e n ě 11 a), que es un playal junto al mar, porque se oye también con la anteposición del artículo.

\section{l) Pedrasmiudas / Pedras-Miúdas}

Cfr. la recomendación dada, para el guión, en el n 311, RIO-TORTO.

m) Plaza del Pan / Praza do Pan

Reivindico la grafía gallega para la pronunciación real de este sitio oída en CORME.

\section{n) Pondal / Pondal}

No es nombre de lugar primitivo — antes bien, parece que era RUEIRO su denominación anterior- ni imposición en honor del bardo de Bergantiños, sino en el de un pariente próximo de Eduardo Pondal, que habrá sido recordado con una calle por la villa de CORME ${ }^{55}$. La abuela materna del poeta era natural de CORME, doña Rosario Mourelle, del apellido del célebre y heroico marino.

\section{p) Remedios / Remedios}

Advocación de Nuestra Señora, con principal festividad en la misma villa, pasada a topónimo urbano.

\section{r) Rúa de los Condes / Rúa dos Condes}

He comprobado en CORME la vigencia popular de la denomina-

${ }^{54}$ PONDAL, E., ed. cit., p. 44.

${ }^{55}$ CARBALLO CALERO, R., Historia da literatura galega contemporánea, I, 1962, p. 233 , nota 4 .

"CUADERNOS DE ESTUDIOS GALLEGOS", Tomo XLI, Fascículo 106, Santiago 1993-94. 
ción gallega. Persisten en esta rúa un escudo y un arco, que no me fue posible examinar. Se trata, probablemente, de restos de la presencia y señorío en CORME de los Condes de Altamira.

\section{s) $\quad$ Sol / Sol}

Se la conoce, a veces, por Calle do Sol, pero el motivo general que he expuesto en la Observación a los topónimos a...s, me inclina a recomendar la forma tal como se la propone en la lista del Ayuntamiento.

\section{Cospindo / Cospindo}

En varios diplomas reales del siglo XII —uno, ya extractado, de Don Fernando II de León, de Junio de 1175; otro del mismo monarca, de 29 de Junio de 1178, y el tercero de su hijo, don Alfonso IX, de 10 de Noviembre de 1189-, se nombra esta feligresía como "...de Curispineto"56, "<ecclesiam> ... Corispenidi" ${ }^{57}$ y "...de Corispenido" 58 , respectivamente.

La sitúan los documentos últimos, con la de Armeretio o Ermerezo, en la tierra de Selagia (Seaya).

Tales formas medievales deponen en favor de una pronunciación romance probable como ${ }^{*}$ Cor $(i)$ spíndo por aquellas fechas y, a mi ver, prestan apoyo a la presunción de una base anterior "C o r i s p in n ě t u m, relacionada, por su precomponente, con el mencionado $* \mathrm{C}$ o r i s s u $\mathrm{m}$ $\mathrm{m}$ a r i u m, que identificamos con CORES. De esa base se conservarían rastros en la transmisión documental u oral previa a los textos que han llegado a nosotros.

El segundo término de composición es posible que debamos emparejarlo con lo que yo presumo origen etimológico del orónimo Pindo < *p i n n ě t u m "el monte peñascos o penedoso".

Requieren todas estas hipótesis —y la fijación, aplicando variados

\footnotetext{
${ }^{56} \mathrm{Cfr}$. en el cuerpo de este informe, III, 000 PONTE-CESO y notas 22 y 23 . El documento del Tumbo de Sobrado, II, fol. 22, está también en GONZÁLEZ, J., Regesta de Fernando II, p. 441.

${ }^{57}$ Se conserva el original en el AHN, carp. 530 n 12 (cfr. SÁNCHEZ BELDA, L., Documentos reales de la Edad Media referentes a Galicia, 1953, $\mathrm{n}^{\circ} 381$, pp. 178-179) y fue reproducido por GONZÁLEZ, J., Regesta de Fernando II, p. 457.

${ }^{58} \mathrm{Cfr}$. en el cuerpo de este informe, III, 400 CORME-ALDEA y nuestra nota 46 bis. Además de la copia del Tumbo de Sobrado, II, fol. 33 v., existe otra copia simple en el AHN, carp. 531, n 20 (SÁNCHEZ BELDA, L., op. cit., n n $^{\circ}$ 435, p. 201).

Nuestro extracto sigue la edición de GONZÁLEZ, J., Alfonso IX, t. II, $\mathrm{n}^{\circ} 31$.
}

"CUADERNOS DE ESTUDIOS GALLEGOS", Tomo XLI, Fascículo 106, Santiago 1993-94. 
criterios, del valor semántico de los compuestos o de sus elementos-, espacio y tiempo apropiados para su desarrollo.

En el dictamen toponímico que nos ocupa baste con subrayar que COSPINDO es forma correcta y preferente, por varias razones, a CUSPINDO, que se ha empleado a veces ${ }^{58 a}$.

\section{Balarés / Balarés}

El topónimo corresponde, conforme a lo que por mí comprobado, a tres sitios diversos.

Se llama así, por de pronto, el lugar poblado de la parroquia de COSPINDO a que se refiere el $\mathrm{n}^{\circ} 601$ del Nomenclator provincial, vecino a la mar, en el punto céntrico del frontón costero tendido entre Laxe y CORME; es, por otra parte, Monte de Balarés el nombre secundario del notable Monte Branco, detrás del susodicho lugar de BALARÉS, enorme empinamiento de arena - "promontorio aquel areoso e vougo"59 - en el brazo Norte de la entrada al estuario de PONTE-CESO; y, por último, reaparece en otra mención toponímica, la del Castelo de Balarés, designando la altura que está a la otra banda de la ría, en la de Laxe, al Sur de Canduas.

Carácter geográfico primario de este estuario y de su contorno lo constituyen las arenas de las dunas, playales y barra. Y al mismo corresponden las notas descriptivas de blancor o brillo en textos, literarios o de otra índole, que atañen a estos parajes cubiertos por las arenas.

Pondal evocó la visión del Monte de Balarés en más de un poema, si bien nunca lo mentó, salvo error mío, con este topónimo.

Por ejemplo,

Monte Branco, Monte Branco,

cando te vexo de lonxe

verto a soas triste pranto... ${ }^{60}$

\footnotetext{
${ }^{58 a}$ La atenuación aún prudente con que establecía en 1979 el étimo *p i n n ě t u m para el orónimo Pindo y como segundo término de composición en Cos-pindo, la descarté no mucho después, una vez comprobada por mí, en otras voces célticas del área luso-galega, la coexistencia de formas con $\bar{e}$ y $\breve{e}$ en el mismo morfema sufijal -ě t o n, tal como también se las encuentra en el celta no hispano. Tiene perfecta explicación en tal duplicidad cuantitativa la contraposición de resultados en el par penedo / Pindo del gallego.

${ }^{59}$ PONDAL, E., ed. cit. pp. 86-87: "...dádelle sepultura / no promontorio aquel soedoso e vougo, / onde o Anllóns, o seu nativo río, / que él máis amou de todos, / da peregrinación antiga súa, / e do longo traballo, hacha repouso".

${ }^{60}$ Ed. cit., p. 88.
}

"CUADERNOS DE ESTUDIOS GALLEGOS", Tomo XLI, Fascículo 106, Santiago 1993-94. 
o en otro lugar,

Dos estéreos areales, que o Oceáno lanzou ós montes, un tempo verdes, soe cubrilos o aquilón

Tí estás coma o Monte-Branco da boca do río Anllóns... ${ }^{61}$

El recurso a la noción de blancura o brillantez en las arenas para nombrar alguno de estos sitios - en concreto, el Monte-Branco - tiene ya precedentes en estos mismos parajes desde la época céltica.

A la misma corresponde, en efecto, el origen indiscutible del topónimo Canduas, al Sur del estero de PONTE-CESO. Pertenece este nuestro topónimo gallego, Canduas, al grupo indoeuropeo de la raíz k a n ds k a n d / s k e n d- "lucir, brillar, esplender", de la que proceden, por ejemplo, el antiguo indio candati "luce, ilumina" o el nombre candana: "sándalo", planta bien oliente que, para aromar, se quema; candra "la luna"; la familia latina de candēre, candor, candidus, etc.; o el galés cann "blanco, brillante", etc. (J. Pokorny, IEW, I, p. 526).

En el léxico común y toponímico de territorios célticos, incluida Galicia, se identifican voces seguras venidas de esta misma raíz, que corroboran la etimología que doy de Canduas. Prescindo de extenderme aquí acerca de ellas.

Era sugerente, en principio, pensar en un étimo análogo para BALARÉS. La raíz indoeuropea b h e l-, b h ə l- "fúlgido, albo, blanco" (IEW, I, pp. 119-120), muy prolífica en céltico, pongamos por caso, que da razón de los teónimos Belenos o Belisama sobrepuestos a los dioses Apolo o Minerva en el panteón galo, o de la que se ha inducido en el mismo galo, a partir de nombres geográficos, una base *b a 1 i o-, se prestaba bien, semánticamente, a una atribución etimológica verosímil para el topónimo BALARÉS.

Pero dos fuertes dificultades obstan a tal hipótesis. Es la primera, que no resulta fácil de conjeturar una forma originaria que justifique, fonéticamente, la conservación de la $-l$ - en el resultado actual y, la segun-

\footnotetext{
${ }^{61}$ Ed. cit., p. 159.
}

"CUADERNOS DE ESTUDIOS GALLEGOS", Tomo XLI, Fascículo 106, Santiago 1993-94. 
da, que tampoco lo es dar con una configuración prerromana de la base que explique el final en -arés de nuestra palabra.

Mas sí que hay, por el contrario, la posibilidad de una base latina que, a mi entender, da cuenta satisfactoria y plena de este topónimo, aclarándosenos gracias a ella el motivo de la disgregación, digámoslo así, del topónimo.BALARÉS en tres puntos diferentes y entre sí distantes, aunque los tres incluídos dentro del área que estamos considerando.

Se trataría de un *v a 11 (e) a r e n e n s e, de donde se habrá seguido $*$ vallarenense $>*_{\text {vallareese }}>$ BALARÉS.

Para la forma y significado del adjetivo, y su proceso de conversión en un topónimo, o mejor dicho, en un corónimo, debe compararse $<\mathrm{t}$ e $\mathrm{r} \mathrm{r}$ a o v a 11 e $>$ s a 1 in e n s e > Salnés.

No se puede excluir, aunque fuese menos probable, que el primer término del compuesto haya sido más bien la voz v a $11 \mathrm{u}(\mathrm{m})$ "vallado o barrera (=duna de arenas)", en esta forma o aún mejor en la del plural neutro tomado por un colectivo singular (compárese castellano valla $<\mathrm{v}$ a $11 \mathrm{a})$ * valla a re ne n s e > BALARÉS.

Creemos que en el étimo que dejamos propuesto se aúnan factores que avalan su plena credibilidad, aunque sea prudente, en tanto no reciba el refrendo del debate a que se brinda toda innovación etimológica, mantener la grafía con B-, que venía utilizándose en el Nomenclator. Una vez ratificada por nuevos datos o por la nulidad de las objeciones, deberá pasar a sustituir oficialmente a la con B- la forma VALARÉS, que es del todo fiel al origen etimológico que acabamos de razonar ${ }^{61 a}$.

\section{Briallo / Briallo}

No presenta dificultades gráficas.

Su base es * b r īg a (c) u l u m "pequeño lugar fuerte; fortín", que deriva de la raíz indoeuropea g "e $\mathrm{r}$ i-, acerca de la cual precaví en otro trabajo mío para que se la deslindase cuidadosamente de la raíz b h rīi $\mathrm{g}$ "altura"62. Sus derivados, casi homófonos, suelen ser confundidos, a lo

${ }^{61 a}$ No conozco objeción alguna, ni las veo hoy con posibilidad de fundamento cierto, al étimo por mí expuesto en 1979. Motivo que debiera ya incitar a la enmienda de su grafía en el Nomenclator.

${ }^{62}$ MILLÁN GONZÁlEZ-PARDO, I., Sobre las aras del santuario de Donón (Hio: Pontevedra) supuestamente dedicadas a Liber, Museo Municipal "Quiñones de León", Vigo, 1978, p. 29.

"CUADERNOS DE ESTUDIOS GALLEGOS", Tomo XLI, Fascículo 106, Santiago 1993-94. 
que coopera la confluencia de sentidos entre "lugar fortificado" y "lugar alto".

De la raíz que nos ocupa proceden en el vocabulario común bríos, brioso y, en el toponímico, Brión. Se aplica éste a varias alturas, con sabidos testimonios algunas de ellas de ocupación castreña ${ }^{62 a}$.

Nuestro BRIALLO de la fel. de COSPINDO se encuentra, según mi información, en una elevación del terreno, pero desconozco si con carácter de castro. En la fel. de San Cristobo de BRIALLOS, ay. Portas, prov. Pontevedra, está documentado un castro y también lo presumo en la aldea de BRIALLOS de la fel. San Julián de Serode, ay. Pantón, prov. Lugo.

\section{Brijería / Brixería}

Mi enmienda gráfica se atiende a lo sentado en el apartado I, $3^{\circ}$.

Se trata, seguramente, de una base prerromana. Hállase en la toponimia gallega algún otro sitio del mismo nombre - Brixaría, lugar de la fel. Santalla de Curtis, ay. Curtis, prov. Coruña ${ }^{63}-$ y otro aún que es sólo posible que tenga próximo parentesco con aquella, Brixela, lug. de la fel. de San Julián de Céltigos, ay. Ortigueira, prov. Coruña ${ }^{64}$.

El problema del exacto encuadre etimológico, que ofrece alguna dificultad, no me detendrá aquí. No excluyo de él, en principio, la raíz $\mathrm{g}$ " e $\mathrm{r}$ i -, que acabo de aducir para BRIALLO, puesto que una base ya céltica comenzando por * b rīg-, postulada por aquellas voces toponímicas, pudiera haber sido continuada por los morfemas - i i a / - i e e.

${ }^{62 a}$ Son 7 los topónimos Brión que extraigo de los índices de la Geogr. Gen. del Reino de Galicia, sitos todos ellos en la actual prov. de Coruña. Hay, además, un Briones (=Brións) en la de Lugo, y veo muy posible que Castrobeon, forma que se lee en algún diploma medieval como designación del monte Castrobe, en la de Pontevedra, proceda de *Castrobrión $<*$ Castrobrigón.

Sendos Briallos corresponden a la de Lugo y Pontevedra. Entiendo ser del mismo origen los topónimos Brías, Brieiro, Briadoiro.

En todos es constante la conservación de la $i$, como venida de $\bar{l}$ larga, lo que desautoriza el intento de HAMP (Homenaje a Tovar, 1972, pp. 177-180) de adjudicar brío y su familia, reincidiendo en la confusión de raíces, a la que dio en irl. brig "altura" o en romance gallego -bre, poscomponente en designaciones de castros.

${ }^{63}$ GG-C, t. II, p. 34.

${ }^{64}$ GG-C, t. II, p. 700.

"CUADERNOS DE ESTUDIOS GALLEGOS", Tomo XLI, Fascículo 106, Santiago 1993-94. 


\section{Cerezo de Abajo / Cerezo de Abaixo}

\section{Cerezo de Arriba / Cerezo de Arriba}

Los comarcanos de PONTE-CESO pronuncian, unánime y cohe-

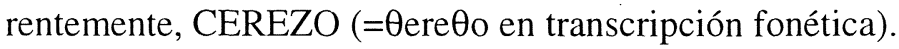

Esta pronunciación está del todo justificada y, por el contrario, es gratuita y errónea la "enmienda" en Cereixo, Sereixo, o en cualquier otra supuesta forma "más correcta" o "más gallega".

Abona esta conclusión, en primer término, la citación documental más antigua que hemos hallado de este topónimo, en la donación ya mencionada del obispo Rudesindo I de Mondoñedo, de 7 de Mayo del año 867. Dice así:

"... Domnis inuictissimis... 'sancto Uincentio... sanctoque Iohanni apostolo... quorum basilica sita est in loco Armeretio, territorio Bragantinos... locum istum Armeretio... cum cunctis procurationibus loci ipsius, omnia, ut superius dictum est, uobis dono atque concedo, siue et terras quas habeo in $S$ e r e t $i$ o similiter offero eidem uestre ecclesie atque concedo..." ${ }^{64}$.

La forma S e r e t i u m excluye, en consecuencia, el emparentamiento con voces gallegas venidas de $\mathrm{c}$ e $\mathrm{r}$ a s e a o de c e r e s e a $\left(\mathrm{REW}^{3} 1823\right)$ o c e r a s u s $\left(\mathrm{REW}^{3} 1824\right)$, así como la presencia de un diptongo en la sílaba medial.

En segundo lugar, la conversión de la S- inicial etimológica en C$(=\theta)$, tampoco se debe a una pronunciación viciosa castellanizante provocada por la analogía de cereza, cerezo, etc., ni es efecto de "ceceo" esporádico, sino que constituye, en mi apreciación, un rasgo idiodialectal del gallego de PONTE-CESO, por asimilación interna, rasgo que está ejemplificado en un texto pondaliano y que se mantiene vivo en la comarca.

Sella Pondal con este refrancillo las estrofas de un poema:

... o trigo é para a fouce aguzada, o érbedo verde ten sua zazón... ${ }^{65}$.

\footnotetext{
${ }^{64 b i s}$ Tumbo de Sobrado, ed. cit. en nota 22, t. I, 1976, $\mathrm{n}^{\circ} 123$, pp. 152-155; lo extractado en la p. 153.

${ }^{65}$ Ed. cit., pp. 54-55.
}

"CUADERNOS DE ESTUDIOS GALLEGOS", Tomo XLI, Fascículo 106, Santiago 1993-94. 
Tanto en s a t i o n e > zazón, cual se oye hoy mismo en tierras de PONTE-CESO, como en $\mathrm{S}$ e r e $\mathrm{t}$ i u $\mathrm{m}>$ Cerezo, se verificó tal asimilación. Es natural, por otra parte, que en el mismo resultado haya influido la ausencia o eliminación del seseo en esta zona -excepto en posición final: des, lus, etc.-, cuya isoglosa pasa al O. de PONTE-CESO, por Canduas o, más precisamente, por Sinde; en Laxe, se sesea francamente.

\section{Couto / Couto $(\mathrm{O})$}

Así se escucha, con el artículo, en los alrededores, y es, sin duda, el término del camino que evoca Eduardo Pondal:

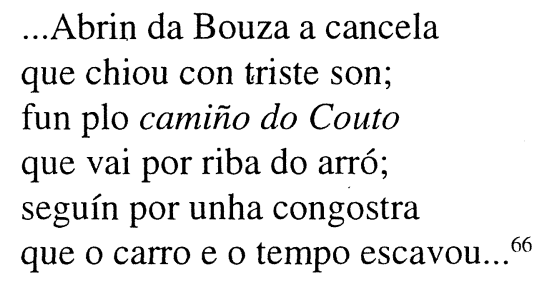

Coincide este lugar, como se deja entender, con tierras que integraban el antiguo acotamiento monacal: c a u $\mathrm{t} \mathrm{u} \mathrm{m}$.

\section{Currás / Currás}

La forma del topónimo es prueba de haberse llegado en esta zona, en la evolución fonética del final latino -a 1 e $\mathrm{s}$, al resultado último que ella acredita, mediante los pasos romances: -aes > -ais >ás.

\section{Graña / Graña (A)}

La parroquia de A GRAÑA continúa en su advocación de San Vicente la del antiquísimo monasterio de Almerezo, a que se refiere el documento de donación y dotación del obispo de Mondoñedo, Rudesindo I, que hemos citado ya un par de veces (nn. 300 CORES, 702 CEREZO).

Con anterioridad al año 867, fecha del diploma, Armeretium pertenecía a un tío del obispo donante, Gavinius de nombre, y se hacía en él vida cenobítica que había compartido el joven Rudesindo, por lo que los orígenes del monasterio, por humildes que hayan sido, es claro que precedían en bastantes años al momento de la donación. Se equivoca Carré

\footnotetext{
${ }^{66}$ Ed. cit., p. 165.
} 
Aldao en la suposición contraria, como también yerra en tomar por San Rosendo, obispo de Santiago en el siglo X, al prelado Rudesindo I de Mondoñedo, de la centuria anterior ${ }^{67}$.

A partir del siglo XII, en virtud, seguramente, de la donación del Rey Fernando II de León en 1175, el monasterio de Armeretio se incorporó al de Sobrado, del Cister, y acabó siendo priorato y granja de la gran abadía bernarda. El término A GRAÑA es indicativo de esta dependencia de la Orden de Claraval y de tal destino y fase de la historia del convento.

La voz toponímica GRAÑA no es, en efecto, otra cosa que la adaptación de la francesa grange $\left(<^{*} \mathrm{~g} \mathrm{r} \text { a } \mathrm{n} \check{\mathrm{i}} \mathrm{c} \text { a }\right)^{68}$, rehecha en gallego, en cierto modo como si derivase de un supuesto * $\mathrm{g} r$ a $n$ e a que habría salido de granum.

No es de este momento comentar todos los casos en Galicia del topónimo GRAÑA en prueba de su carácter últimamente monacal.

En San Vicente de A GRAÑA perseveró el priorato cisterciense hasta la época de la exclaustración, en el siglo pasado, y se convirtió después en anejo, posteriormente suprimido, de la iglesia de San Tirso de COSPINDO $^{69}$. López Ferreiro se inclina al parecer de que el templo actual no se levanta en el mismo sitio en que estuvo ubicado el antiguo monasterio de $\mathrm{Almerezo}^{70}$, y son escasos, según otros testimonios, los restos atribuidos a éste ${ }^{71}$. No me fue dado, en mis cortas estancias en PONTE-CESO, llegar a estos parajes ${ }^{71 a}$.

\section{Lestimoño / Lestimoño}

Se ha aportado ya un texto antiguo (cfr. 000, PONTE-CESO) con la inclusión de este topónimo, en el documento del Rey Fernando II de León, de 1175, por el que donó a Sobrado las iglesias de Almerezo y COSPINDO:

${ }^{67}$ GG-C, t. II, p. 205.

${ }^{68} \mathrm{REW}^{3} 3845, * \mathrm{~g}$ r a n i c a.- Cfr. DAUZAT, A., Dictionnaire étymologique de la lengue française, 1938, p. 372, s.v. Grange.

${ }^{69}$ GG-C, t. II, p. 205 y LÓPEZ FERREIRO, A., Historia de la S.A.M.I. de Santiago de Compostela, t. II, 1899 , pp. 262-263 y nota 3.

${ }^{70}$ op. et loc. cit. en nuestra nota anterior; para Rudesindo véanse, además, pp. 180-181.

71 "De él <el convento de Almerezo> no quedan restos, sino el recuerdo en los documentos": CARRÉ ALDAO, E., GG-C, t. II, p. 205.

${ }^{71 a}$ Con posterioridad a 1979, tuve ocasión de conocerlos y recorrerlos en bastante extensión, guiado y asesorado con suma amabilidad y competencia por el Párroco de San Martiño de Cores, don Cándido Rodríguez Campaña. No puedo incorporar ya a estas notas algunas interesantes observaciones hechas en Cores y sus contornos.

"CUADERNOS DE ESTUDIOS GALLEGOS", Tomo XLI, Fascículo 106, Santiago 1993-94. 
"... per locum quo diuiditur hereditates uille

Telie et uille Lestimonii.."72.

Forma y pronunciación romances eran ya, de seguro, como las de hoy $^{72 a}$.

\section{0-803 Jornes / Xornes}

El cambio de grafía se ajusta a lo expresado en el apartado I, $3^{\circ}$.

Es aún cuestionable el étimo que corresponde a XORNES. La fel. de San Xoán de XORNES, a la derecha del Anllóns, está regada por dos arroyos que traen sus aguas a este río, bajando el uno por el E. y otro por

72 ed. et loc. cit. en nuestra nota 22.

${ }^{72 a}$ Comunico por vez primera en esta nota el étimo de LESTIMOÑO. Es un topónimo compuesto de dos elementos netamente célticos. Siempre se atisbó la relación del primero de ellos con lesta, nombre de la "grama adorífera" (=anthoxanthum odoratum L.), que nuestros labradores aprecian, o apreciaban, "como exquisito forraje que en muchos puntos cultivan" (MERINO S.I., B., Flora... de Galicia, t. III, 1909, nº 1.537, pp. 248-249).

También ha sido por lo general admitido el parentesco de lesta "grama de olor" con los topónimos LESTEDO, LESTIDO, LESTROBE, entre otros. Bastaba con ello para inferir el carácter prerromano de la voz lesta, puesto que LESTROBE < *LESTOBRE, es denominación de un castro antiguo y, por otra parte, la oposición de sus terminaciones en LESTEDO / LESTIDO obedece a una colisión bilíngüe a lo largo de nuestro territorio en época de convivencia romano-céltica, en que los hablantes del celta luso-galeco convertían la $-\bar{e}$ - en $-i-$, mientras que los del latín, o ya habituados a él, mantenían como tal la $-\bar{e}$ larga, o la restauraban.

Expuse este hecho, y sus consecuencias, en mi conferencia en el Curso Internacional de la Universidad Menéndez Pelayo, convocado bajo el lema de Los celtas en Europa y los celtas hispanos, IX. 1982. Fue asunto de mi exposición Los celtas del NO hispano: aspectos lingüísticos.

Sabido, además, que el lit. lèsti tiene, entre otros significados, el de "recoger grano, seleccionar" y el irl. lestar el de "vasija" y el córn. y bretón lestr el de "barco, buque < de carga >", descansando el semantema común en el concepto de "cesta, canasta, recipiente de recolección de granos, bayas o frutos análogos" y, por añadidura, que el gót. lisan "cosechar, reunir", anglosajón lesen "reunir", confluyen en la misma idea, no se presta a dificultad concluir que el valor primitivo de lesta consintió en un sentido especificado de "forraje: hierbas o granos o pastos secos que se reúnen y dan por alimento al ganado".

No encierra tampoco mayor obstáculo el sentido del poscomponente -moño, venido de una de las formas del céltico para "monte": * m o n i i o (IEW, p. 726). No es ningún otro el origen del hispano moño, etimología que ahorra la innecesaria excursión divagatoria por la base, también conjeturada, de la voz BOÑIGA (COROMINAS, J., DCECH, t. IV, 1981, pp. 133-134).

LESTIMOÑO constituye una elevación del terreno aunque ignoro si, hoy mismo, carece de lestas, o abundan aún en él, justificando su antiguo nombre: "colina o altura poblada de lestas".

"CUADERNOS DE ESTUDIOS GALLEGOS", Tomo XLI, Fascículo 106, Santiago 1993-94. 
el O. del término parroquial. No se puede descartar, entre las posibilidades etimológicas, la de la raíz hidronímica s e r-, s o r-, s a r- (IEW, I, pp. 908-910), de cuyo grado apofónico en -o- son muestra en Galicia los ríos Sor, Sorga, etc.

Para la palatalización de la S- inicial se hallan otros paralelos léxicos como lo viene a ser, en última cuenta, el caso del Xallas $<\mathrm{S}$ a 1 i a (s), perteneciente a distinto grupo hidronímico. Carezco aún de suficientes datos documentales y, sobre todo, observaciones topográficas, que me permiten asegurar esta hipótesis ${ }^{72 b}$.

\section{Froján / Froxán} 404).

Aplíquesele lo dicho, en general, para el FROXÁN de CORME ( $n^{\circ}$

${ }^{72 b}$ La recapacitación en torno a los datos recogidos en 1979 me permite hoy apoyar, con más firme fundamento, la sugerencia hecha entonces de una base etimológica dependiente de la raíz hidronímica s e r -, s o r-, s a r- (IEW, pp. 908-910).

Consistiría esa base en una de las varias formas adoptadas por dicha raíz, cuya idea general era la de "movimiento rápido y fuerte; corriente, flujo". Sería la forma requerida la de * s orna.

Aparece en Galicia este nombre, por una sola vez que yo sepa, como mero topónimo de una aldea de San Pedro de Coucieiro, ay. Muxía, Coruña (GG-C, II, p. 258). Se encuentra esta aldea a la orilla del río del Castro, el cual desemboca, tras un recorrido desde la sierra al E. de Vimianzo, en la ensenada entre Nemiña y Lires. He estado en Coucieiro y sus alrededores varias veces, y llegado a la conclusión hace tiempo de que Sorna era nombre propio del río, que captó y con qué pasó a llamarse este lugar de sus riberas. Porque, en efecto, la voz $\mathrm{S}$ o r n a no encierra ningún otro valor significativo que el hídrico, que es el propio de su familia léxica.

Esta reflexión lingüística, y la topográfica de la feligresía de XORNES, del ay. de PONTE-CESO, sita en medio de dos ríos menores que confluyen a la gran corriente del Anllóns, despeja las incógnitas de la forma y significado del topónimo. Se trata, a lo que deduzco, de un locativo de plural, * S o r $\mathrm{n}$ i s, equivaliendo a "entre ríos" o "entre ambos ríos".

Ni la palatalización de la $s$ - inicial en voces de este origen, dando XORNES, ni el uso de locativo en topónimos, precisan de explicación que las justifique. He dado noticia de uso tanto en algunos de origen céltico-Correxíns de c o r r u g īn i s-como en otros de origen latino Arís de a e r i f o dīn i s, Ordes de h or de i s, Herbes de $\mathrm{H}$ e r b i s-. Hay bastantes más.

Un respaldo concluyente al S o $\mathrm{n}$ a de Coucieiro, como denominación céltica originaria del río que fluye junto a él, es idéntico potamónimo, S o r n a, en la Baja Alsacia, junto a Hagenau, tierra de los antiguos celtas mediomatrici. Era $\mathrm{S}$ o r $\mathrm{n}$ a aún en los siglos VII-VIII, es Zorn en nuestros días (HOLDER, AS, II, 1904, c. 1617).

"CUADERNOS DE ESTUDIOS GALLEGOS", Tomo XLI, Fascículo 106, Santiago 1993-94. 


\section{Sergude / Sergude}

Exento de problemas gráficos, se debe tener en cuenta, para la interpretación de su significado, la existencia de otros SERGUDE en la toponimia gallega.

Se tiene, por de pronto, la fel. de San Verísimo de SERGUDE, ay. de Boqueixón, p.j. Santiago, prov. Coruña ${ }^{73}$. Además, un lugar SERGUDE en la fel. de Santa María de Vilaquinde y un SERGUDIÑO en la limítrofe de San Miguel de Oleiros, ambas a orillas del Búbal, en el ay. Carballedo, p.j. Chantada, prov. Lugo ${ }^{74}$. Existe aún otro SERGUDE, aldea que está a la vera de un arroyuelo, afluente del Avia, en la fel. de San Fiz de Navio, ay. de San Amaro, p.j. Carballiño, prov. Ourense ${ }^{75}$.

\section{Melcos / Melcos}

Tampoco, en cuanto a su grafía, ofece dificultades. Trae consigo este lugar de la fel. de LANGUEIRÓN un enriquecimiento de nuestra lexicografía, puesto que melcos, como apelativo común, que desconocen los léxicos gallegos por mí manejados, parece ser usado en puntos de esta comarca como término agrario - ¿pequeña propiedad o leira? - que no me ha sido aún posible asegurar.

No sé de otro ejemplo de MELCOS en toponimia gallega, pero sí hay un MELCAS, lugar de la fel. de San Salvador de Coruxo, ay. y p.j. de Vigo, Pontevedra ${ }^{76} / 76 \mathrm{~b}$.

\section{Vitureira / Vitureira (A)}

Su étimo es * v ŭ lt ŭ rār i a "nidal de buítres".

Además del de XORNES, hay otro sitio denominado VITUREIRA cerca del Monte Branco o BALARÉS, por tanto no alejado del que nos ocupa, si no me engañan las fuentes cartográficas que manejo.

Ambos resultados coincidentes, concordarían, a su vez, con las tendencias fonéticas de la zona, donde se pronuncia escuita, muito, luita, nuite, etc. En un resultado *vuitureira acabaría por haber adquirido pre-

\footnotetext{
${ }^{73}$ GG-C, t. II, pp. 1062-1063.

${ }^{74}$ GG-L, p. 359. Hay otro lugar que llaman Seragude en San Juan de Frontón, ay. Pantón, Lugo (GG-L, p. 604). No me parece dudoso que represente una forma anaptítica de SERGUDE.

${ }^{75}$ GG-O, p. 476.

${ }^{76}$ GG-P, p. 954.

${ }^{76 b}$ Los barruntos que por ahora tengo de su empleo agrario me hacen sospechar el origen célt. *ambel(i)kos $>*$ ammelkos $>$ amelcos / melcos "surco o franja de deslinde, siembra o rodeo, en una haza o leira". (Cfr. DCECH, t. I, s.v. amelga, p. 240-241).
}

"CUADERNOS DE ESTUDIOS GALLEGOS", Tomo XLI, Fascículo 106, Santiago 1993-94. 
dominio el timbre y acento de la - $i$-, esfumándose la primera - $u$ - en gracia a la de la sílaba siguiente.

Está registrado un lugar de Bitureiro ( $<^{*} \mathrm{v}$ u $1 \mathrm{t}$ u rā r i u m) en la fel. de San Ciprián de Monte Cubeiro, ay. Castroverde, p.j. y prov. de Lugo ${ }^{77}$ y se conoce un riachuelo Boutureira en el ay. de Barbadás, prov. Ourense ${ }^{78}$.

\section{Nemeño / Nemeño}

\section{Nemeño / Nemeño}

Las menciones documentales más antiguas que he localizado de NEMEÑO se identifican, constantemente, con la base léxica $\mathrm{N}$ e m e n i o, que postula casi por fuerza la forma actual de este topónimo.

Se encuentra la primera en la escritura de donación ya extractada (cfr. $\mathrm{n}^{\circ} 300$ CORES), por la que tres particulares dieron sus bienes, en 14 de Diciembre del año 860, a las iglesias de San Tirso, de San Martín y de los santos Julián y Basilisa:

. "qorum basilicas sunt fundatas in uilla que dicitur Corissomario. qui est territorio Bragantinos..., ex medietate de pumare quod est hic in Corissumario iuxta sanctum Martinum et uillan quam obtinuit Felix que est inter Castrum et Nemenio cum domibus suis que ibi sunt fundatis, seu et uineam et pumares quos Felix ibi plantauit, siue et terram pannales quas me (sic) obtinuit in ipsa uilla..."79.

A dos siglos y pico de esta fecha se otorgaron otros dos documentos que, con el tiempo, pasarían a pertenecer al archivo del Real Monasterio de Santa María de Sar.

Es el primero de ellos, de 18 de Septiembre de 1078, una donación de lugar de $\mathrm{N}$ e m e $\mathrm{n}$ i o al monasterio de NEMEÑO, hecha por Vilifonso Gundesindiz y su esposa Animia ${ }^{80}$. Consiste el segundo en otra donación al mismo monasterio concedida por el Conde Don Pedro Froilaz y su es-

\footnotetext{
${ }^{77}$ GG-L, p. 235.

${ }^{78}$ GG-O, pp. 303, 335.

${ }^{79}$ ed. cit. en nuestras notas 22 y 41 .

${ }^{80}$ Galicia Diplomática, t. I, 1882, nº 1, pp. 3-6: El Archivo del Real Monasterio de Sar, por B. BARREIRO DE V.V.
}

"CUADERNOS DE ESTUDIOS GALLEGOS", Tomo XLI, Fascículo 106, Santiago 1993-94. 
posa Doña Guntroda ${ }^{81}$. López Ferreiro adjudicó al año 1105 este diploma de donación a NEMEÑO de los Condes de Traba y señala como su redactor al abad Recamundo, que lo era del monasterio de Santiago de $M e n s^{82}$.

Santo Tomé de NEMEÑO se incorporó hacia el año 1433, siendo en aquel momento convento de canónigos regulares de San Agustín, al monasterio de $\mathrm{Sar}^{83}$.

En el aspecto lingüístico, NEMEÑO encaja en una familia léxica indoeuropea, la de la raíz n e m- "distribuir o repartir; prender, tomar" (J. Pokorny, IEW, I, pp. 763-764, s.v.) que tuvo muy viva representación en céltico y ha dejado testimonios variados de esta procedencia en la toponimia gallega: Nendos (<n e m ě t o s), Nemancos, Neme, Nemiña...

\section{Niñones / Niñóns}

\section{Niñones / Niñóns}

Esta corrección expulsará de una vez el feo castrapismo del actual Nomenclator, conforme al criterio que ya se propugnó en I, $4^{\circ}$.

Pondal evoca el fiero mar de NIÑÓNS - junto a la Costa de Bar$d a$ - en el refrán de un poema en que bosqueja una autosemblanza:

...parece un pino leixado do vento, parece botado do mar de Niñóns... ${ }^{84}$

No sé que se haya intentado establecer, hasta el momento en que escribo, el étimo de esta voz geográfica. Lo es, a mi entender, $\mathrm{N}$ e m e $\mathrm{n}$ i o lo s, base que ya aparece en un documento que fue aludido en mi nota anterior.

Las fases fonéticas de la evolución se rehacen de la siguiente mane-

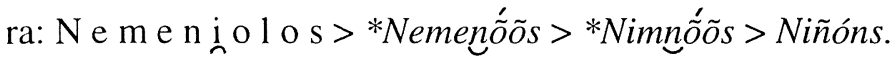

Es otro dato comprobante de la vitalidad de la raíz céltica de que hice ponderación. El monte Neme al E. de la comarca de PONTE-CESO,

\footnotetext{
${ }^{81}$ Se contiene la noticia en el art. cit. en nuestra nota anterior, en su p. 5, mas rectifíquese la data conforme a la referencia de LÓPEZ FERREIRO, que se aduce en la nota que sigue a esta.

${ }^{82}$ Ojeada sobre el estado de los monasterios de Galicia a fines del siglo XI y principios del siguiente, en Galicia Histórica, t. I (1901), n 1, pp. 45-58. La referencia de nuestro interés, en la p. 54.

${ }^{83}$ Cfr. art. cit. en nuestra nota 80, p. 5 , en la nota de aquél a pie de página.

${ }^{84}$ ed. cit., pp. 17-18.
}

"CUADERNOS DE ESTUDIOS GALLEGOS", Tomo XLI, Fascículo 106, Santiago 1993-94. 
y la comarca de Nemancos o el lugar de Nemiña al SO de la misma, son otros tantos hitos del substrato céltico en esta zona.

\section{Ameijenda / Ameixenda}

Se efectúa el cambio de grafía conforme a la norma de I, $3^{\circ}$, ya aplicada en FROXÁN, GUXÍN, BRIXERÍA, XORNES y que, por el contrario, vigía ya en PAXARIÑA, SEIXOS.

El étimo será *d a m a s c e n e t a "plantel de ciruelos o ameixas", tal como lo supone para este mismo caso Moralejo ${ }^{85}$ si en el mismo no se ha de excluir la intromisión de algún derivado de a d m i s c ē r e <a q u a s $>$, origen que da razón de formas fonéticamente próximas.

\section{0-1305 Tallo / Tallo}

Nada hay que modificar en este nombre de lugar, que lo es asimismo de la fel. de San Andrés de TALLO.

El estudio del étimo, que es incierto, requiere la comparación y, acaso, el deslinde de otros topónimos análogos que se encuentran en Galicia. Se llaman Tallos dos lugares de la prov. de Lugo, el uno en la fel. de Santa María de Cuína, ay. de Palas de Rei ${ }^{86}$ y el otro en la de San Esteban de Eirexealba, ay. de Incio ${ }^{87}$. Tallón es nombre de lugar en la fel. de Santa María de Macendo, ay. de Castrelo de Miño, Ourense ${ }^{88}$ y de otro de San Pedro de Toedo, ay. de A Estrada, Pontevedra ${ }^{89}$. Parece constituir su plural el topónimo Tallós, que corresponde a una aldea de la fel. de San Juan de laíño, ay. de Dodro, Coruña ${ }^{90}$ y a otra de Santa Cristina de Valeixe, ay. de A Caniza (=La Cañiza), Pontevedra ${ }^{91}$.

Al lado de estos tenemos un Tállara, que denomina a una parroquia de la advocación de San Pedro, ay. de Lousame, p.j. de Noya, Coruña ${ }^{92}$ y a un río que pasa por ella, y Tallobre, que denomina un lugar de la fel. de Santiago de Oubiaño, ay. de Fonsagrada, Lugo ${ }^{93}$.

\footnotetext{
${ }^{85}$ Toponimia gallega y leonesa, p. 343-344.

${ }^{86}$ GG-L, p. 370.

${ }^{87}$ GG-L, p. 761.

${ }^{88}$ GG-O, P. 675.

${ }^{89}$ GG-P, p. 552.

${ }^{90}$ GG-C, t. II, p. 788.

${ }^{91}$ GG-P, p. 501.

${ }^{92}$ GG-C, t. II, p. 558. Para el río, ibid. y p. 516.

${ }^{93}$ GG-L, p. 398.
}

"CUADERNOS DE ESTUDIOS GALLEGOS", Tomo XLI, Fascículo 106, Santiago 1993-94. 
No se puede aún determinar la filiación latina de algunos de estos topónimos —en conexión con t a 1 e a "retoño; vástago, estaca, tallo, arbolillo de plantel" y con t a l i à r e > cast. "tajar, cortar"—o, acaso, la prelatina de otros o de su mayor parte. Confróntense, en efecto, Tállara, Tallobre, que transparentan raigambre de substrato.

\section{Vilasuso / Vilasuso}

No precisa cambio: véase lo escrito arriba en el $n^{\circ} 313$, VILADESUSO. Mis testimonios, algunos por conducto indirecto, dan para este lugar la forma que mantengo.

\section{Tella / Tella}

Tampoco pide cambio. En el ${ }^{\circ} 000$ PONTE-CESO se ha extractado el pasaje de la escritura de 1175, de Fernando II de León, en que se mencionan, como linderos de la donación hecha a Sobrado.

"... per iuncale de Telia et inde per locum quo diuiditur hereditates uille Telie..."

La latinización medieval de la Cancillería regia espeja una pronunciación romance igual, o muy próxima, a la de hoy, pero no es lícito tomarla como la base primitiva de nuestra voz, que tampoco puede, por consiguiente, ser aún dilucidada con seguridad respecto a su étimo.

Pondal, en su famoso poema E tí, campana de Anllóns, pone el recuerdo de este sitio en labios del cautivo bergantiñán:

"...río de Ponte-Ceso,

pinal de Tella espeso...,

acordávos dun preso

como el o fai de vós...

\section{Calle / Calle (A)}

Todos los informantes de PONTE-CESO que pude interrogar coincidieron en proporcionarme la forma A C A L L E (=kale) de este topónimo y no otra alguna. Es la que debe perseverar en el Nomenclatory en la señalización local, por el criterio invocado en I, $5^{\circ}$, de la posesión real y plena que manifiesta esta forma entre los hablantes gallegos de la comarca, quienes repelerían la sustitución. Hago además reserva, por mi parte, de problemas lingüísticos y etimológicos que la afectan y que no se han puesto aún suficientemente en claro.

Pues plantean, en efecto, los posibles derivados del latín c a 11 i s

"CUADERNOS DE ESTUDIOS GALLEGOS", Tomo XLI, Fascículo 106, Santiago 1993-94. 
"sendero: trocha de pastores o ganado; camino de monte" (REW $\left.{ }^{3} 1520\right)$, incógnitas no resueltas en el léxico común y toponímico galaico-portugués.

Por lo de pronto, el resultado esperado, cale / cal, como de v a 11 is $>$ vale, val, se pudo prestar a confusiones de forma o significación con los del latín c a n a l i s (REW $\left.{ }^{3} 1568\right)$, que produjo en gallego, normalmente, canle. El convencimiento de la existencia de estas confusiones fue motivo que debió de pesar sobre Meyer-Lübke para abstenerse de registrar en el artículo ya citado para c a 11 i s, en el REW ${ }^{3} 1320$, descendiente ninguno suyo lusitano ni gallego.

Pero es evidente que éstos se dieron, aunque prescinda yo aquí de puntualizar en qué grado los representan los distintos significados y ejemplos del apelativo común gallego cale / cal, a saber: 1) "canal de aguas"; 2) "surco de arado"; 3) "cañada o paso entre montes" 95.

Ciñéndome a la toponimia recogida en los tomos de la Geografía General del Reino de Galicia, editada por F. Carreras y Candi, constan en sus cuatro provincias, salvo yerro mío, un Cale en la de Coruña ${ }^{96}$ por seis Cal en la misma ${ }^{97}$; catorce $\mathrm{Cal}$ en la de Lugo ${ }^{98}$; cuatro en la de Ourense ${ }^{99}$

\footnotetext{
${ }^{94}$ ed. cit., p. 107.

${ }^{95}$ RODRÍGUEZ GONZÁLEZ, E., Dicc. encicl. gall.-castell., t. I, 1958, p. 436.

${ }^{96}$ Lug. en San Julián de Barbos, ay. Ortigueira: GG-C, t. II, p. 697.

${ }^{97}$ Son los siguientes: Lug. en San Esteban de Loureda, ay. Cesuras: GG-C, I, p. 871. Lug. en Santa María de Maroxo, ay. Arzúa: GG-C, II, p. 20. Lug. en Santa María de Neda. ay. Neda: GG-C, II, p. 336. Lug. en San Julián de Lamas, ay. San Saturnino: GG-C, II, p. 344. Lug. en San Julián de Céltigos, ay. Ortigueira: GG-C, I, p. 700. Lug. en San Pedro de Cervás, ay. Ares: GG-C, II, p. 845.

${ }^{98}$ Su lista es la siguiente: Lug. en Santa María de Ferreira, ay. Guntín: GG-L, p. 263. Lug. en Santo Tomé de Lourenzá, ay. Lourenzá: GG-L, p. 531. Lug. en San Esteban de Espasantes, ay. Pantón: GG-L, p. 604. Lug. en San Vicente de Deade, ay. Pantón: GG-L, p. 604. Lug. en Santa María de Ousende, ay. Sabiñao: GG-L, p. 610. Lug. en San Juan de Barantes, ay. Sover: GG-L, p. 616. Lug. en San Esteban de Calvor, ay. Sarria: GG-L, p. 747. Lug. en San Esteban de Vilouzán, ay. Láncara: GG-L, p. 770. Lug. en Santa Eufemia de Vilarmosteiro, ay. Páramo: GG-L, p. 784. Lug. en San Simón da Costa, ay. Vilalba: GGL, p. 812. Lug. en Santa María de Tardad, ay. Vilalba: GG-L, p. 813. Lug. en Santa María de Labrada, ay. Trasparga: GG-L, p. 850. Lug. en Santiago de Trasparga, ay. Trasparga: GG-L, p. 851.

${ }^{99}$ Son los siguientes: Lug. en San Pedro de Xunqueira, ay. Tribes: GG-O, p. 588. Lug. en San Lorenzo de Tribes, ay. Tribes: GG-O, p. 591. Lug. en San Payo de Abeleda, ay. Castro Caldelas: GG-O, pp. 596-597. Lug. en Santa María de Prado, ay. Castrelo de Miño: GG-O, p. 675.
}

"CUADERNOS DE ESTUDIOS GALLEGOS", Tomo XLI, Fascículo 106, Santiago 1993-94. 
y uno en la de Pontevedra ${ }^{100}$.

Para el plural, Cales, se hallan dos en Lugo ${ }^{101}$, uno en Ourense ${ }^{102}$ y otro en Pontevedra ${ }^{103}$.

Aparece además el término adjetivado en Cal-boa ${ }^{104}$, Calgrande ${ }^{105}$, Cal-<l>ousada ${ }^{106} \mathrm{y}$, seguido de otras terminaciones, en Cal-deMoreiras $^{107}$, Cal-de-Barcos ${ }^{108}$, Cal-de-Vilar ${ }^{109}$, Cal-de-Samed ${ }^{110}$, Cal-daLoba ${ }^{111}$, Cal-do-Sapo ${ }^{112}$, Cal-da-Pena ${ }^{113}$, Cal-da-Revolta ${ }^{14}$, Cal-deMourelle $^{115}$, Cal-de-Rei ${ }^{116}$ y Cal-de-Outeiro ${ }^{117}$.

Contra estos cuarenta y cuatro ejemplos de Cale / Cal / Cales, solo o en compañía, compruebo cinco casos de Calle y dos de Calles, nombrando 1 u g a re s de feligresías r u r a l e s en la provincia coruñesa ${ }^{118}$, dos

\footnotetext{
${ }^{100}$ Lug. en San Pedro de Tenorio, ay. Cotobade: GG-P, p. 330.

${ }^{101}$ Es un lug. en Santiago de Adelán, ay. Alfoz: GG-L, p. 994 pero, además, un riachuelo Cales en tierra de Cervantes: GG-L, p. 300.

${ }^{102}$ Lug. en Santa María de Ucelle, ay. Coles: GG-O, p. 317.

${ }^{103}$ Lug. en San Juan de Chenlo, ay. Porriño: GG-P, p. 847.

${ }^{104}$ Nombra una punta costera, llamada también Mallón de Lires, en la linde entre Lires y Cee: GG-C, II, p. 226.

${ }^{105}$ Nombre de monte, en San Pedro de Roupar, ay. Xermade, Lugo: GG-L, p. 839.

${ }^{106}$ Nombre de Lug. en San Pedro de Roupar, ay. Xermade, Lugo: GG-L, p. 839.

${ }^{107}$ Nombre de entidad en Loureiro, junto a San Pedro de Visma, cerca de Coruña: GGC, I, p. 427.

${ }^{108}$ Punta marina, ensenada y aldea en San Mamed de Carnota, ay. Carnota, Coruña: GG-C, II, pp. 402-404.

${ }^{109}$ Lug. en Santa María de Xestoso, ay. Monfero, Coruña: GG-C, I, p. 886.

${ }^{110}$ Lug. en San Tirso de Ambroa, ay. Irixoa, Coruña: GG-C, t. I, p. 886.

${ }^{111}$ Lug. en San Martín do Pino, ay. Cospeito, Lugo: GG-L, p. 833.

${ }^{112}$ Lug. en Santiago de Viveiro, ay. Viveiro: GG-L, p. 878.

${ }^{113}$ Lug. en San Miguel de Orbazay, ay. Lugo: GG-L, p. 130.

${ }^{114}$ Lug. en San Vicente da Pena, ay. Begonte, Lugo: GG-L, p. 822.

${ }^{115}$ Lug. en San Esteban de Ansar, ay. Taboada, Lugo: GG-L, p. 389. Lug. en Santa Mariña de Cerdeda, ay. Taboada, Lugo: GG-L, p. 390.

${ }^{116}$ Nombre de riachuelo, afluente del Ladra, Vilalba, Lugo: GG-L, pp. 52, 274.

${ }^{117}$ Lug. en San Jorge de Sayáns, ay. Vigo. Pontevedra: GG-P, p. 959.

${ }^{118}$ Se denominan Calle, en la provincia de Coruña, además del lugar CALLE de Santo Outel de TELLA, en el ay. de PONTE-CESO, los siguientes: Lug. en San Julián de Sergude, ay. Carral: GG-C, I, p. 737. Lug. en Santa María de Sarandóns, ay. Abegondo: GG-C, I, p. 837. Lug. en Santa María de Urdilde, ay. Rois: GG-C, II, p. 807. Lug. en San Julián de Poulo, ay. Ordes: GG-C, II, pp. 606, 617.

Se denominan Calles: Lug. en San Esteban do Campo, ay. Arzúa: GG-C, II, p. 18. Lug. en San Lorenzo das Olas, ay. Mesía: GG-C, I, p. 650.
}

"CUADERNOS DE ESTUDIOS GALLEGOS", Tomo XLI, Fascículo 106, Santiago 1993-94. 
Calle en la de Lugo ${ }^{119}$, ninguno en la de Ourense y dos en la de Pontevedra ${ }^{120}$, aparte de Calle de Ferreiros, Calle das Rocas, Calle Nova y Calle Real, en otras tantas parroquias $\mathrm{r}$ u $\mathrm{r}$ a 1 e $\mathrm{s}$ de la provincia de Coruña ${ }^{121}$. Harían quince en total, aun sin cribar estas últimas, que podrían ser más problemáticas.

Una simple ojeada a la estadística y distribución, y a la peculiaridad rural de bastantes Calle, me inclina a admitir que denotan la penetración, o ya presencia, de la voz castellana o de la pronunciación castellanizante, para designar algún tipo de camino, desde una época que remontaría, en ciertos casos, al siglo XVI. Esta mi deducción requeriría una investigación complementaria, en buena parte documental, de todos y cada uno de ellos.

El arraigo que parecen haber adquirido, en sitios como el de San Andrés de TELLA, en PONTE-CESO, depone a favor de esta introducción muy antigua: pluricentenaria.

Dejo al margen de estas consideraciones la de si hubo, o no, en la Galicia prerromana, algún derivado de una raíz próxima a la del latino c a 11 i s, que resulta ser el origen del antiguo irlandés caill "bosque; senda en el bosque, trocha", y que juega como uno de los étimos probables de nuestros Callobre ${ }^{122}$. Formaciones sobre esta raíz pudieran, en tal supuesto, haber influido en el fonetismo de Calle. Pero, en el instante en que escribo, tengo la hipótesis por mucho menos aceptable que la explicación

${ }^{119}$ Figuran con el nombre de Calle en la provincia de Lugo: Lug. en Santiago de Trasmonte, ay. Friol: GG-L, p. 257. Lug. en San Martín de Siós, ay. Pantón: GG-L, p. 605.

${ }^{120}$ Se denominan Calle en esta provincia: Lug. en Santiago de Arcade, ay. Soutomaior: GG-P, p. 766. Lug. en San Cristóbal de Goyán, ay. Tomiño: GG-P, p. 865.

${ }^{121}$ Calle de Ferreiros es la denominación de dos lugares de parroquias limítrofes, la de San Verísimo y la de San Mamed de Ferreiros, ay. Pino, Coruña: GG-C, t. II, p. 66-67. Calle das Rocas se dice ser un lugar de Santa María de Castro, en ay. de Narón: GG-C, t. II, p. 320. Calle Nova sería otro de Santa María de Caranza, ay. Serantes: GG-C, t. II, p. 353. Calle Real lo sería de Santa María de Oleiros, ay. Oleiros: GG-C, t. I, p. 765.

${ }^{122}$ Corresponden a las siguientes localizaciones los topónimos Callobre en Galicia: Callobre, en San Xoán de Callobre, ay. Miño, Coruña: GG-C, II, p. 873. Callobre, lug. en Santa María de Cuíña, ay. Oza dos Ríos: GG-C, I, p. 896. Callobre, en San Julián de Céltigos, ay. Ortigueira: GG-C, II, p. 700. Callobre, topónimo antiquísimo en la ciudad de Santiago de Compostela, el cual pervivió mucho tiempo como designación en el callejero urbano: cfr. MORALEJO LASSO, A., Toponimia gallega y leonesa, p. 51-52. Callobre, por último, en San Martín de Callobre, ay. de A Estrada, Pontevedra: GG-P, pp. 354-355

"CUADERNOS DE ESTUDIOS GALLEGOS", Tomo XLI, Fascículo 106, Santiago 1993-94 
que he anticipado ${ }^{122 a}$.

\section{Gándara / Gándara (A)}

Es muy frecuente oír A GÁNDARA, por lo que recomiendo esta forma.

Aprovecho esta nota para consignar que la "geada" está muy extendida en la zona y con ella, además de $a g^{h}$ ándara, he oído: $a g^{h} a r g^{h} a$, fig ${ }^{h}$ eiroa, $g^{h}$ ondomil, $g^{h} u x i ́ n$, candelag ${ }^{h}$ o, a reg ${ }^{h}$ adiña, $a^{h}$ a raña, lang ${ }^{h}$ eirón

${ }^{i 22 a}$ El estudio sobre El topónimo céltico Callobre y primera cala en su familia léxica, publicado en el tomo de Homenaje a Don Antonio Couceiro Freijomil, Diputación Provincial de A Coruña, 1991, pp. 199-218, me hizo abandonar del todo la desestimación manifestada en 1979 respecto a la procedencia céltica de los antiguos y extrañísimos topónimos Calle, arraigados en zonas rurales y en proporción residual, de los que había reunido en aquel año los quince ejemplos mencionados en las notas 119-121.

A la posible investigación de todos ellos, así comparativa como individualizada, anticipo las siguientes consideraciones.

Tanto el latino c a ll i s como el irlandés antiguo c a i 11 con significación ambos de "camino agreste o de montaña: trocha, sendero, vereda", proceden de idéntica base indoueuropea, * $\mathrm{k}$ a l n i -, que pasó en estas dos ramas dialectales a una forma con asimilación del grupo -ln- en -ll-, es decir, a * c a 11 i - (cfr. art. cit., pp. 205-206).

Resultado del latín c a ll i s / c a ll e (m) es el castell. calle y en gallego, a través de un $\mathrm{c}$ a l e, procede últimamente cal, en manera del todo análoga a como del latín $\mathrm{v}$ a $\mathrm{l}$ l i s $/$ $\mathrm{v}$ a $1 \mathrm{l}$ e (m) se produjo el castell. valle y en gallego, por intermedio de $\mathrm{v}$ a l e, últimamente val.

Que no haya testimonio alguno del uso en gallego, ni en la toponimia ni en el habla común, de una forma *valle para designar esta frecuentísima configuración de un terreno, mientras que sí la hay de calle como apelativo -consolidado en la toponimia- de "sendero, camino rural", se debe a que derivaba esta última voz de una fuente y por cauce idiomáticos diferentes y previos a los del latín.

El antiguo irlandés caill, "semita ferarum", o "terrarum" en mss. del Glosario de Cormac, pronunciado c a 1 - es decir, con un fonema último análogo al de la $l l$ en castellano-, fue término final de la evolución * $\mathrm{k}$ a l n i $>* \mathrm{c}$ a l-l i $>* \mathrm{c}$ a l-l e e > c a l.

Impulsó este proceso la infección fonética ejercida por la vocal palatal $i$ de la última sílaba. Ya en antiguo irlandés esta vocal última, vacilante, llegó a perderse, mientras que en los topónimos rurales de origen céltico que perduraron en gallego está representada la fijación de la fase * c a l-1 e e o c a l e e de la evolución de esta voz en el gaélico primitivo.

En la grafía caill, la -i- carecía en sí misma de pronunciación y es tan sólo signo de la articulación palatal del dígrafo consonántico que la seguía, conforme al precepto ortográfico y ortológico de asociar con sus semejantes, en escritura y dicción, fonemas palatales o no palatales: "estrecho con estrecho y ancho con ancho" (caol le caol agus leathan le leathan).

No estaba esta voz $\mathrm{c}$ a l e = calle "sendero de monte, camino agreste, aldeano", aislada o sin parientes en el celta luso-galaico: callau, callo, Callobre, aparte de otras muchas que aún no he publicado, pertenecían a la misma familia. (Cfr. El topónimo céltico Callobre y primera cala en su familia léxica, citado al principio de esta misma nota).

"CUADERNOS DE ESTUDIOS GALLEGOS", Tomo XLI, Fascículo 106, Santiago 1993-94. 
(pero otras veces, sin "geada", langueirón y lengueirón), as salgheiras... Excuso añadir que concuerdo en absoluto con los que proscriben su normalización gráfica, sea cualquiera la opinión que sustenten sobre el origen y carácter de este fenómeno en el habla.

\section{Vereda / Vereda}

Mis informantes me han proporcionado, con constancia, la forma cuya perduración en el Nomenclator recomiendo. Sólo una detenida búsqueda en viejos documentos podría cerciorarnos de si la pronunciación hoy consolidada es mera repristinación de la primitiva base de un gallego Brea, abandonado éste por los hablantes, o si se trata más bien de un término culto o semiculto introducido en la toponimia de la zona en siglos no alejados, para denominar el sólito itinerario del correo o posta o de los avisos y mensajerías emanados de los órganos de la jurisdicción eclesiástica o civil, bien fuese comarcal o provincial o central.

Estas son las voces geográficas que, en razón de los diversos motivos expuestos en el apartado I, $6^{\circ}$, nos ha parecido más oportuno comentar.

Había aún otras que se prestaban también a glosas explicativas, pero tendrían éstas menor incidencia para el abocetamiento de rasgos históricos sumarios de la comarca de PONTE-CESO, o no era en ellas aplicable la recomendación de un cambio o de un mantenimiento gráfico, o bien encerraban menor alcance o utilidad en los aspectos lingüísticos de un estudio toponomástico.

Mi estancia en Grecia e Italia durante los meses de SeptiembreOctubre dilató hasta el mes en que lo suscribo la redacción de este dictamen. Salvo mejor información o criterio, me ratifico en las consideraciones y recomendaciones que en él formulo y que envío, para los efectos que estimen más procedentes, al Ilustrísimo Ayuntamiento de PONTECESO. Santiago de Compostela, a 23 de Noviembre de 1979 . 